\title{
Superior arsenate adsorption and comprehensive investigation of adsorption mechanism on novel Mn-doped $\mathrm{La}_{2} \mathrm{O}_{2} \mathrm{CO}_{3}$ composites
}

\author{
Jing Su ${ }^{\mathrm{a}, \mathrm{b}}$, Tao $\mathrm{Lyu}^{\mathrm{c}, \mathrm{d}}$, Hao $\mathrm{Yi}^{\mathrm{e}}$, Lei Bi ${ }^{\mathrm{a}, *}$, Gang Pan ${ }^{\mathrm{a}, \mathrm{b}, \mathrm{c}, \mathrm{d}, *}$ \\ ${ }^{a}$ Key Laboratory of Environmental Nanotechnology and Health Effects, Research Center for Eco-Environmental Sciences, Chinese Academy of Sciences, Beijing 100085, PR \\ China \\ ${ }^{\mathrm{b}}$ University of Chinese Academy of Sciences, Beijing 100049, PR China \\ ${ }^{\mathrm{c}}$ School of Animal, Rural, and Environmental Sciences, Nottingham Trent University, Brackenhurst Campus, NG25 OQF, UK \\ ${ }^{\mathrm{d}}$ Centre of Integrated Water-Energy-Food Studies (iWEF), Nottingham Trent University, Nottinghamshire NG25 OQF, UK \\ ${ }^{\mathrm{e}}$ School of Resources and Environmental Engineering, Wuhan University of Technology, 122 Luoshi Road, Wuhan, Hubei 430070, PR China
}

\section{H I G H L I G H T S}

- Mn-doped $\mathrm{La}_{2} \mathrm{O}_{2} \mathrm{CO}_{3}$ (MnL) exhibited superior arsenate capture capacity of $555.6 \mathrm{mg} / \mathrm{g}$.

- The residual of As(V) was well below the permissive value for drinking water.

- Doping with Mn atoms enhanced adsorption sites and reduced adsorption energy.

- Surface complex and anion exchange dominated As(V) removal at low As (V)/MnL ratios.

- Forming $\mathrm{LaAsO}_{4}$ precipitates contributed greatly at high $\mathrm{As}(\mathrm{V}) / \mathrm{MnL}$ ratios.

\section{A R T I C L E I N F O}

\section{Keywords:}

Atoms doping

Adsorption energy

Lanthanum compounds

Arsenate removal
G R A P H I C A L A B S T R A C T

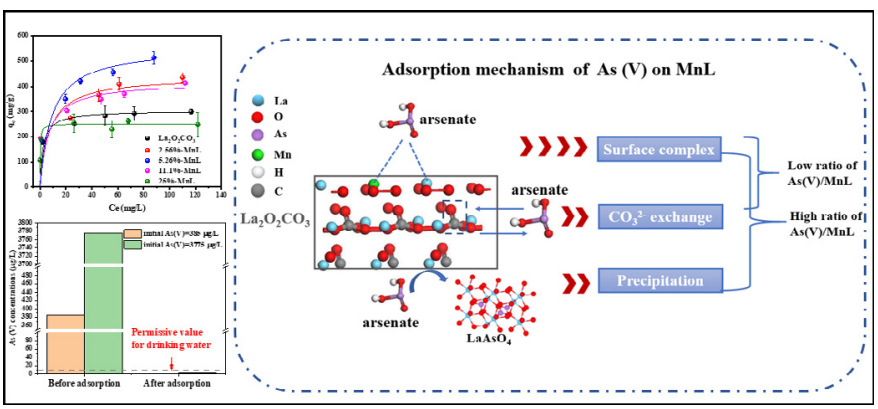

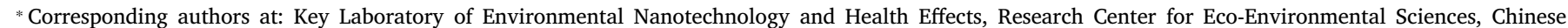
Academy of Sciences, Beijing 100085, PR China (G. Pan, L. Bei).

E-mail addresses: leibi@rcees.ac.cn (L. Bi), gpan@rcees.ac.cn (G. Pan). 
towards arsenate, $\mathrm{Mn}$-doped $\mathrm{La}_{2} \mathrm{O}_{2} \mathrm{CO}_{3}$ has been demonstrated to be a promising prospect for the remediation of arsenate-polluted water.

\section{Introduction}

Contamination of water bodies by arsenic causes a severe threat to the environment and human health, even at low concentrations, owing to its toxicity, mutagenicity and carcinogenicity [1-3]. In addition to the natural wreathing of arsenic enriched minerals, the anthropogenic activities including mining, industrial processes and agricultural practices, also substantially contribute to the arsenic pollution [4-6]. Typically the arsenate, $\mathrm{As}(\mathrm{V})$, is the prevalent species of arsenic especially in natural surface waters [7]. Therefore, the development of the arsenate decontamination technology is highly desirable towards environmental sustainability and public health.

Among the current arsenate removal technologies, adsorption is regarded as a promising technology with the advantages of simplicity in operation, low cost and without yielding harmful by-products [8]. Numerous adsorbents, such as metal oxides/bimetallic oxides [1,9], porous MOFs [10,11] and modified activated carbon [3], have been synthesized for the purpose of arsenate removal. However, most of them still suffered from the limited adsorption capacity. In order to further enhance performance, a variety of efforts have been undertaken to address challenges in materials development, including increasing the number of adsorption sites as well as promoting surface activities in order to strengthen chemical interactions and to reduce the adsorption energy during adsorption process.

Doping with heteroatoms, especially transition metal atoms could be a promising strategy to improve arsenate removal, by increasing porosity, active sites (i.e. hydroxyl groups) and by changing electronegativity of synthesized adsorbents [9]. Several metal oxides doped with transition metal atoms, such as $\mathrm{Cu}$ doped $\mathrm{Fe}_{3} \mathrm{O}_{4}$ [9], zinc ferrite spinel $\left(\mathrm{Zn}_{\mathrm{x}} \mathrm{Fe}_{3-\mathrm{x}} \mathrm{O}_{4}\right)$ [12] and $\mathrm{Ce}$ doped $\mathrm{TiO}_{2}$ [13] have been well explored. Manganese $(\mathrm{Mn})$, as a typical transition metal with more variable valence states than $\mathrm{Cu}, \mathrm{Zn}$ and $\mathrm{Ce}$, is hypothesized to accelerate electron transfer between $\mathrm{As}, \mathrm{O}$ and $\mathrm{Mn}$ and to act as adsorption sites for arsenate by forming the Mn-O-As complex [14,15]. Previous studies have reported the significantly improved performance for arsenate removal by double layer hydroxide [15], $\mathrm{Fe}_{2} \mathrm{O}_{3}$ [16] and $\mathrm{Fe}_{3} \mathrm{O}_{4}$ [17], after doping with $\mathrm{Mn}$ atoms. However, these materials still have restrictions, particularly under high arsenate concentrations, due to the inherent limited sorption capabilities of those traditional $\mathrm{Fe} / \mathrm{Al}$ based materials [18]. In addition, the hypothesized mechanisms of Mn atoms on arsenate adsorption processes is yet to be fully demonstrated.

Lanthanum oxycarbonate $\left(\mathrm{La}_{2} \mathrm{O}_{2} \mathrm{CO}_{3}\right)$, a derivative of $\mathrm{La}_{2} \mathrm{O}_{3}$ with exchangeable $\mathrm{CO}_{3}{ }^{2-}$, has recently attracted great interest due to the high chemical activity exhibited in catalysis and adsorption applications $[19,20] . \mathrm{La}_{2} \mathrm{O}_{2} \mathrm{CO}_{3}$ has recently been proved to be an efficient adsorbent to capture phosphate $[20,21]$. To best of our knowledge, few studies have been conducted to date using $\mathrm{La}_{2} \mathrm{O}_{2} \mathrm{CO}_{3}$ for arsenate removal, although phosphorous and arsenic are in the same group, possessing chemical similarities [11]. It is known that $\mathrm{La}(\mathrm{III})$ in $\mathrm{La}(\mathrm{OH})_{3}$ has a strong affinity to arsenate due to the Lewis acid-base adduct formed by ligand exchange [22]. $\mathrm{La}_{2} \mathrm{O}_{2} \mathrm{CO}_{3}$, with a large amount of intrinsic $\mathrm{La}(\mathrm{III})$ and exchangeable groups $\left(\mathrm{CO}_{3}{ }^{2-}\right.$ and $\left.\mathrm{O}^{2-}\right)$, is hypothesized to exhibit great potential for arsenate capture. Therefore, through the substitution the conventional $\mathrm{Fe} / \mathrm{Al}$ based adsorbent to $\mathrm{La}_{2} \mathrm{O}_{2} \mathrm{CO}_{3}$ and coupling with $\mathrm{Mn}$ atoms doping is expected to achieve a novel arsenate adsorbent to overcome both limitations of lack of adsorption sites and of weak interaction between arsenate and adsorbent.

In this study, we synthesised Mn-doped $\mathrm{La}_{2} \mathrm{O}_{2} \mathrm{CO}_{3}(\mathrm{MnL})$ as a novel adsorbent for arsenate decontamination. Firstly, arsenate removal performance, kinetics and isotherms were evaluated to obtain an optimised composition of Mn for the MnL synthesis. Then, the adsorption performance was investigated under various $\mathrm{pH}$ conditions (4.3-9.1) and in the presence of competing anions (such as $\mathrm{SO}_{4}{ }^{2-}$, $\mathrm{SiO}_{3}{ }^{2-}, \mathrm{HPO}_{4}{ }^{-}$and $\mathrm{HCO}_{3}{ }^{-}$). The reusability of $\mathrm{MnL}$ after desorption was also evaluated. Additionally, the adsorption mechanism was explored by employing various characterization techniques. Finally, Density Functional Theory (DFT) calculations were performed in order to understand the functions that $\mathrm{Mn}$ atoms have on arsenate removal at the molecular level. With these results, this study has aimed to suggest a novel, highly efficient adsorbent for arsenate removal, with clearly elucidated mechanisms of reaction.

\section{Materials and methods}

\subsection{Materials}

All chemicals used were analytical grade reagents. $\mathrm{Na}_{3} \mathrm{AsO}_{4} \cdot 12 \mathrm{H}_{2} \mathrm{O}$ and $\mathrm{La}\left(\mathrm{NO}_{3}\right)_{3} \cdot 6 \mathrm{H}_{2} \mathrm{O}(99 \%)$ was obtained from Aladdin Industrial Co. Ltd. (Shanghai, China). $\mathrm{Mn}\left(\mathrm{NO}_{3}\right)_{2}(50 \%)$, citric acid monohydrate $\left(\mathrm{C}_{6} \mathrm{HO}_{7} \cdot \mathrm{H}_{2} \mathrm{O}\right)$ and polyethylene glycol 6000 (PEG-6000) were purchased from Sinopharm Co. LTD. (Shanghai, China). Ultrapure water $(18 \mathrm{M} \Omega \cdot \mathrm{cm})$ was used in all experiments.

\subsection{The synthesis of $\mathrm{Mn}$-doped $\mathrm{La}_{2} \mathrm{O}_{2} \mathrm{CO}_{3}(\mathrm{MnL})$}

Mn-doped $\mathrm{La}_{2} \mathrm{O}_{2} \mathrm{CO}_{3}$ was synthesized by a Sol-Gel method with some modifications [23]. Briefly, certain amount of $\mathrm{Mn}\left(\mathrm{NO}_{3}\right)_{2}$ and $\mathrm{La}$ $\left(\mathrm{NO}_{3}\right)_{3} \cdot 6 \mathrm{H}_{2} \mathrm{O}$, with molar ratios of $\mathrm{Mn} /(\mathrm{La}+\mathrm{Mn})$ equalled to $2.56 \%$, $5.26 \%, 11.1 \%$ and $25 \%$, respectively, were dissolved in ultrapure water $(20 \mathrm{~mL})$ and stirred vigorously for $30 \mathrm{~min}$. Then, the mixtures were added into aqueous solution $(20 \mathrm{~mL})$ composed of $\mathrm{C}_{6} \mathrm{HO}_{7} \cdot \mathrm{H}_{2} \mathrm{O}$ (0.01 mol) and PEG-6000 (6 g). The solutions were heated to $85{ }^{\circ} \mathrm{C}$ with continuously stirring until the formation of a wet gel. After drying overnight at $85^{\circ} \mathrm{C}$, the gels were calcined in the air $\left(600{ }^{\circ} \mathrm{C}\right.$ for $120 \mathrm{~min}$; heating rate of $5{ }^{\circ} \mathrm{C} / \mathrm{min}$ ). After cooling, the solid samples were finely grinded and labelled as $\mathrm{x}-\mathrm{MnL}$, where $\mathrm{x}$ represented the molar ratio of $\mathrm{Mn} /(\mathrm{La}+\mathrm{Mn})$. Pure $\mathrm{La}_{2} \mathrm{O}_{2} \mathrm{CO}_{3}$ was also prepared by this process but without manganous nitrate addition. Moreover, $\mathrm{LaMnO}_{3}$ was also synthesized according to the method reported previously [24] and detailed process was stated in Supplementary Information (S1).

\subsection{Adsorption experiments}

In order to evaluate the optimal composition of $\mathrm{MnL}$ and the relevant adsorption behaviours, both the $\mathrm{x}-\mathrm{MnL}(\mathrm{x}=2.56 \%, 5.26 \%$, $11.1 \%, 25 \%$ ) and $\mathrm{La}_{2} \mathrm{O}_{2} \mathrm{CO}_{3}$ were used for the arsenate removal kinetics and isotherm experiment. For the kinetics experiment, adsorbents $(10 \mathrm{mg})$ were added into solutions of arsenate ions $(100 \mathrm{~mL} ; 50 \mathrm{mg} / \mathrm{L})$ with an initial $\mathrm{pH}$ of 7 . The solutions were then shaken in the dark at $130 \mathrm{rpm}$ for $48 \mathrm{~h}$ at $25{ }^{\circ} \mathrm{C}$. At different time intervals, a $1.5 \mathrm{~mL}$ aliquot of supernatant was collected and filtered through a $0.22 \mu \mathrm{m}$ cellulose acetate membrane for arsenate concentration determination. Pseudofirst order, pseudo-second order and intraparticle diffusion models were employed to simulate the experimental data (Supplementary Information, S2)

Regarding to the adsorption isotherm study, identical amounts of adsorbents $(0.1 \mathrm{~g} / \mathrm{L})$ were added into solutions with initial arsenate concentrations varying from 10 to $150 \mathrm{mg} / \mathrm{L}$. The initial $\mathrm{pH}$ of mixture solution was 7. After shaken at $130 \mathrm{rpm}$ for $72 \mathrm{~h}$ at $25{ }^{\circ} \mathrm{C}$, the final solutions were filtered and analysed for the arsenate concentration. The 
Langmuir and Freundlich isotherm models were applied to simulate experimental data (Supplementary Information, S2). The arsenate removal efficiency $(\eta)$, adsorption capacity $\left(q_{e}\right)$ and the distribution coefficient $\left(K_{d}\right)$ were calculated as follows:

$\eta=\frac{\left(C_{0}-C_{e}\right)}{C_{0}} \times 100 \%$

$q_{e}=\frac{\left(C_{0}-C_{e}\right) \times V}{m}$

$K_{d}=\frac{V}{m} \frac{C_{0}-C_{e}}{C_{e}} \times 1000$

where $\eta(\%)$ is arsenate removal efficiency, $q_{e}(\mathrm{mg} / \mathrm{g})$ is adsorption capacity in equilibrium state and $K_{d}(\mathrm{~mL} / \mathrm{g})$ represents the distribution coefficient of adsorbents in arsenate solution. $C_{0}$ and $C_{e}$ are the initial and equilibrium concentrations of arsenate in solution $(\mathrm{mg} / \mathrm{L})$, respectively. $V(m L)$ is the volume of arsenate solution and $m(m g)$ is the mass of adsorbent.

In order to study the influence of initial $\mathrm{pH}$ on the adsorption performance, the adsorption capabilities of both the optimal composite (5.26\%-MnL) and pure $\mathrm{La}_{2} \mathrm{O}_{2} \mathrm{CO}_{3}$ were determined under different $\mathrm{pH}$ conditions ranging from 4.3 to 9.1 . $\mathrm{NaOH}$ or $\mathrm{HNO}_{3}(0.1-1 \mathrm{~mol} / \mathrm{L})$ were used to adjust to the desired initial $\mathrm{pH}$ before the adsorption test. The experimental conditions and sampling procedures were the same as for the aforementioned isotherm study. The effect of coexisting anions, such as $\mathrm{SO}_{4}{ }^{2-}, \mathrm{SiO}_{3}{ }^{2-}, \mathrm{HPO}_{4}{ }^{-}$and $\mathrm{HCO}_{3}{ }^{-}$, on arsenate removal was also evaluated. During this adsorption test, $\mathrm{SO}_{4}{ }^{2-}, \mathrm{SiO}_{3}{ }^{2-}, \mathrm{HPO}_{4}{ }^{-}$and $\mathrm{HCO}_{3}{ }^{-}$at the concentration of $10 \mathrm{mg} / \mathrm{L}$ and $100 \mathrm{mg} / \mathrm{L}$ were added separately into arsenate solution $(10 \mathrm{mg} / \mathrm{L})$. After $24 \mathrm{~h}$ reaction, a $1.5 \mathrm{~mL}$ aliquot solution was removed and filtered for arsenate quantification. In addition, the possible reutilisation of $5.26 \%$-MnL was evaluated through three cycles of adsorption-desorption. Due to the strong interaction between $\mathrm{As}(\mathrm{V})$ and La, a harsh method, such as soaking in $\mathrm{NaOH}$ solution (0.05-1 M), was generally applied for arsenate desorption $[1,10,25]$. Therefore, $1 \mathrm{~mol} / \mathrm{L} \mathrm{NaOH}$ solution was used as elution agent in this study. During each adsorption, the initial arsenate concentration was set as $10 \mathrm{mg} / \mathrm{L}$ and the dosage of adsorbents was fixed as $0.2 \mathrm{~g} / \mathrm{L}$. After $12 \mathrm{~h}$ reaction, $1.5 \mathrm{~mL}$ of supernatant was sampled in order to determine As (V) removal efficiency. The adsorbent material was then collected and placed into $1 \mathrm{M} \mathrm{NaOH}(50 \mathrm{~mL})$ for desorption treatment. After $24 \mathrm{~h}$ of elution, the supernatant was sampled to determine elution efficiency. The regenerated materials were then collected and dried under vacuum for the next adsorption-desorption cycle. All the aforementioned adsorption experiments were conducted in duplicate and each sample quantification was conducted in triplicate.

\subsection{Characterization}

The crystal structures of adsorbents before and after the adsorption test were determined by X-Ray diffraction (XRD) using a PANalytical X'Pert PRO powder diffraction system (Malvern Panalytical, Cambridge, UK) with $\mathrm{Cu}$ Ka radiation $(\lambda=1.5406 \AA)$ from $5^{\circ}$ to $90^{\circ} / 2 \theta$ at a scan speed of $5^{\circ} / \mathrm{min}$. The morphology of the samples and their microstructure were recorded by Field Emission Scanning Electron Microscopy (FESEM, Su-8020, Hitachi, Japan) and high-resolution Transmission Electron Microscopy (HRTEM, JEM-2010, JEOL, Japan), respectively. X-ray Photoelectron spectra (XPS; SCALAB250Xi, Thermo Fisher Scientific, USA) were collected with a monochromatic Al Ka radiation source (1486.6 eV) and all binding energies were calibrated by contaminant carbon (C1s, B.E $=284.8 \mathrm{eV}$ ). Fourier Transform Infrared spectra (FTIR; Nicolet 8700, Thermo Fisher Scientific, USA) were collected over the wavenumber range of $4000-500 \mathrm{~cm}^{-1} \cdot \mathrm{N}_{2}$ adsorption and desorption isotherms of adsorbent were recorded on a Micromeritics ASAP-2020 system (Micromeritics Instrument Corp., USA). Prior to analysis, sample were degassed at $150{ }^{\circ} \mathrm{C}$ for $4 \mathrm{~h}$ under vacuum. Surface area determinations were made by the BET method. Zeta potentials of adsorbents was obtained by Zetasizer Nano ZS90 (Malvern instruments, UK).

\subsection{Analytical and computational methods}

In addition to the concentration of arsenate, $\mathrm{La}^{3+}$ and $\mathrm{Mn}^{2+}$ concentrations in solution were measured by Inductively Coupled PlasmaOptical Emission Spectroscopy (ICP-OES; Optima 8300, Perkin Elmer Inc., USA) with a detection limit of $0.2 \mathrm{mg} / \mathrm{L}$. It should be noted that Inductively Coupled Plasma-Mass Spectrometry (ICP-MS; 7500a, Agilent Inc. USA) was used to confirm results when concentration levels were found to be below $0.2 \mathrm{mg} / \mathrm{L}$. Both $\mathrm{CO}_{3}^{2-}$ and $\mathrm{HCO}_{3}^{-}$in solution were determined by acid-base titration, where detailed procedures were presented in the Supplementary Information (S3). Density Functional Theory (DFT) calculations were performed based on experimental results where the method described in the Supplementary Information (S4).

\section{Results and discussion}

\subsection{Characterization of synthesised adsorbents}

The diffraction peaks of pure $\mathrm{La}_{2} \mathrm{O}_{2} \mathrm{CO}_{3}$ in XRD patterns (Fig. 1a) could be well matched to monoclinic $\mathrm{La}_{2} \mathrm{O}_{2} \mathrm{CO}_{3}$ with lattice constants of $\mathrm{a}=4.08 \AA, \mathrm{b}=13.51 \AA$ and $\mathrm{c}=4.07 \AA$ (JCPDS card No. 48-1113). The doping of $\mathrm{Mn}$ atoms would change the symmetry of $\mathrm{La}_{2} \mathrm{O}_{2} \mathrm{CO}_{3}$ from monoclinic to tetragonal (JCPDS card 23-0320) with constants of $\mathrm{a}=4.06 \AA, \mathrm{b}=4.06 \AA$ and $\mathrm{c}=13.5 \AA$, indicating that Mn doping led to a crystalline transformation of $\mathrm{La}_{2} \mathrm{O}_{2} \mathrm{CO}_{3}$ from type Ia to type I. No
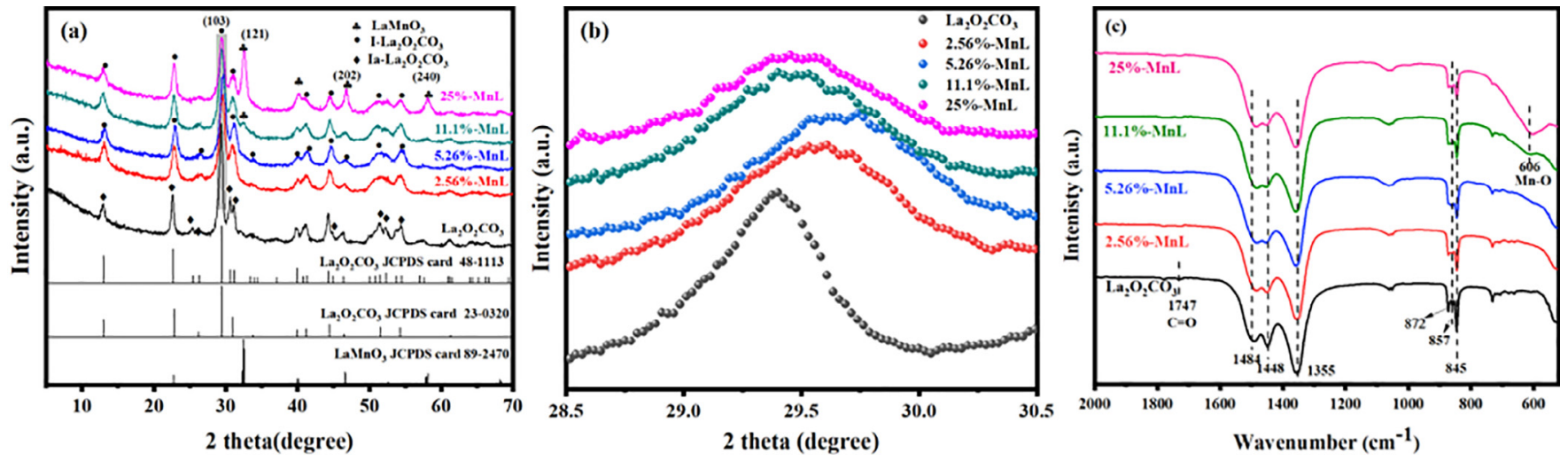

Fig. 1. XRD patterns of $\mathrm{x}-\mathrm{MnL}$ and $\mathrm{La}_{2} \mathrm{O}_{2} \mathrm{CO}_{3}$ from 5 to $70^{\circ}$ (a) and 28.5-30.5 (b). The FTIR spectra of $\mathrm{x}-\mathrm{MnL}^{\circ}$ and $\mathrm{La}_{2} \mathrm{O}_{2} \mathrm{CO}_{3}$ (c). 
clear peak for manganese oxide was observed in $\mathrm{x}-\mathrm{MnL}$ when $\mathrm{x}$ was as low as $2.56 \%$ or $5.26 \%$, which may be due to the formation of La-Mn solid solution [26] or highly distributed $\mathrm{Mn}$ species on $\mathrm{La}_{2} \mathrm{O}_{2} \mathrm{CO}_{3}$ [27]. However, perovskite-type oxides $\mathrm{LaMnO}_{3}$ (JCPDS card No. 75-0440) occurred when $\mathrm{x}$ values were higher, such as $11.1 \%$ and $25 \%$, which suggested a new phase of MnL would be precipitated when excess Mn atoms were introduced during synthesis. Additionally, the position of (1 0 3) plane of $\mathrm{La}_{2} \mathrm{O}_{2} \mathrm{CO}_{3}$ began to shift to higher values as the content of $\mathrm{Mn}$ increased to $5.26 \%$ (Fig. $1 \mathrm{~b}$ ). This is mainly because the radii of $\mathrm{Mn}^{2+} / \mathrm{Mn}^{3+} / \mathrm{Mn}^{4+}\left(\mathrm{Mn}^{2+}=0.91 \AA, \mathrm{Mn}^{3+}=0.65 \AA\right.$, $\mathrm{Mn}^{4+}=0.54 \AA$ ) are much lower than $\mathrm{La}^{3+}(1.06 \AA)$ [28] and substitution of $\mathrm{La}^{3+}$ by $\mathrm{Mn}^{2+} / \mathrm{Mn}^{3+} / \mathrm{Mn}^{4+}$ would cause shrinkage of the unit cell. However, continued increase in Mn content resulted in the position of ( $\left.\begin{array}{lll}1 & 0 & 3\end{array}\right)$ peak turning back to lower values, probably because of the formation of $\mathrm{LaMnO}_{3}$ which might incorporate into (LaO) ${ }^{+}$ layers, leading to slight cell expansion. By dissolving $\mathrm{x}-\mathrm{MnL}$ with aqua regia and detecting the total $\mathrm{Mn}$ and La content in solution, the Mn/ $(\mathrm{Mn}+\mathrm{La})$ molar percentages of $\mathrm{x}-\mathrm{MnL}$ were determined to be $2.60 \%$, $5.40 \%, 11.3 \%$ and $26.8 \%$, corresponding to $2.56 \%-\mathrm{MnL}, 5.26 \%-\mathrm{MnL}$, $11.1 \%-\mathrm{MnL}$ and 25\%-MnL respectively. The small differences between theoretical and practical values of $\mathrm{Mn} /(\mathrm{Mn}+\mathrm{La})$ suggested that all of the Mn precursor had been incorporated into the La species successfully to form a solid solution.

From the FTIR spectra of pure $\mathrm{La}_{2} \mathrm{O}_{2} \mathrm{CO}_{3}$ (Fig. 1c), the peaks at 845, $872,1355,1448,1484 \mathrm{~cm}^{-1}$ are characteristic peaks of oxycarbonates, suggesting the presence of $\mathrm{CO}_{3}{ }^{2-}$ between layers of $(\mathrm{LaO})^{+}[29,30]$. The weak peak at $1747 \mathrm{~cm}^{-1}$ may be assigned to $\mathrm{C}=\mathrm{O}$ stretching of $\mathrm{La}_{2} \mathrm{O}_{2} \mathrm{CO}_{3}$ species [29]. It should be noted that for $\mathrm{x}-\mathrm{MnL}$, the peaks related to $\mathrm{CO}_{3}{ }^{2-}$ were gradually weakened while the $\mathrm{Mn}-\mathrm{O}$ located at $606 \mathrm{~cm}^{-1}$ [31] become more noticeable as the value of $\mathrm{x}$ increased. This result indicated that there were more $\mathrm{LaMnO}_{3}$ species present at high $\mathrm{Mn} / \mathrm{La}$ ratios. Moreover, the position of La-O located at $857 \mathrm{~cm}^{-1}$ [2] changed little over various $\mathrm{x}$ values, indicating that $\mathrm{Mn}$ did not markedly change the coordination environment of $\mathrm{La}^{3+}$.

Based on images from FESEM analysis, the pure $\mathrm{La}_{2} \mathrm{O}_{2} \mathrm{CO}_{3}$ presented agglomerated irregular spherical structures with an average size of 50-100 nm (Fig. 2a), while x-MnL exhibited rod-like morphologies of differing lengths (Fig. 2b-c). Similar results have been previously reported that atomic doping might notably change the pristine crystalline morphology $[11,26]$. The HRTEM images clearly revealed that the fringes in pure $\mathrm{La}_{2} \mathrm{O}_{2} \mathrm{CO}_{3}$ were intact and prominent, implying good crystallinity (Fig. 2d). The lattice fringe with a spacing distance of $0.309 \mathrm{~nm}$ was in a good agreement with the $\left(\begin{array}{lll}1 & 0 & 3\end{array}\right)$ plane of $\mathrm{La}_{2} \mathrm{O}_{2} \mathrm{CO}_{3}$. With lesser amounts of Mn doping, such as in 5.26\%-MnL, the lattice spacing decreased from 0.309 to $0.303 \mathrm{~nm}$ (Fig. 2e), consistent with the result of the contracted unit cell. Abundant lattice defects were observed in $5.26 \%-\mathrm{MnL}$, probably deriving from the substitution by $\mathrm{Mn}$ species. It has been reported that lattice defects could enhance the adsorption capabilities of metal (hydro)oxides towards various pollutants (i.e. CO, organic dyes and phosphate), probably by providing extra active adsorption sites [32-34]. Considering this, 5.26\%-MnL was hypothesized to show better adsorption efficiencies towards arsenate than pristine $\mathrm{La}_{2} \mathrm{O}_{2} \mathrm{CO}_{3}$. After further increasing the amount of $\mathrm{Mn}$ to $25 \%$, the rod structures became shorter and thicker (Fig. 2c). The fringe distance of $0.273 \mathrm{~nm}$ could be attributed to the $\left(\begin{array}{lll}1 & 2 & 1\end{array}\right)$ plane of $\mathrm{LaMnO}_{3}$ (Fig. 2f), indicating the formation of the new phase. There were lattice fringe distortions rather than defects in $25 \%-\mathrm{MnL}$, which may due to the overlapped crystals. It was hypothesized that crystals of $\mathrm{LaMnO}_{3}$ had been precipitated on the surface, which overlapped the support of $\mathrm{La}_{2} \mathrm{O}_{2} \mathrm{CO}_{3}$. The morphologies of $2.56 \%-\mathrm{MnL}$ and $11.1 \%-\mathrm{MnL}$ were similar to $5.26 \%-\mathrm{MnL}$ although with more broken rods and fragments, and with less lattice defects and overlaps evident (Fig. S1).

$\mathrm{N}_{2}$ adsorption and desorption isotherms of both $\mathrm{x}-\mathrm{MnL}$ and $\mathrm{La}_{2} \mathrm{O}_{2} \mathrm{CO}_{3}$ exhibited Type I-shaped curves (Fig. S2), indicating that $\mathrm{Mn}$ doping did not markedly affect the microporous structure of the material. Moreover, the surface area of these materials remained in the range $9.28 \mathrm{~m}^{2} / \mathrm{g}$ to $11.16 \mathrm{~m}^{2} / \mathrm{g}$. Although pure $\mathrm{La}_{2} \mathrm{O}_{2} \mathrm{CO}_{3}$ particle sizes were smaller, they were likely to agglomerate due to nanometer effect, thus limiting any sharp increase of surface area.

\subsection{Arsenate adsorption behaviour}

\subsubsection{Adsorption kinetics}

Pristine $\mathrm{La}_{2} \mathrm{O}_{2} \mathrm{CO}_{3}$ exhibited a relatively slow adsorption rate and lower adsorption efficiency towards arsenate (Fig. 3a). In comparison, $5.26 \%-M n L$ exhibited the best adsorption efficiency in which more than
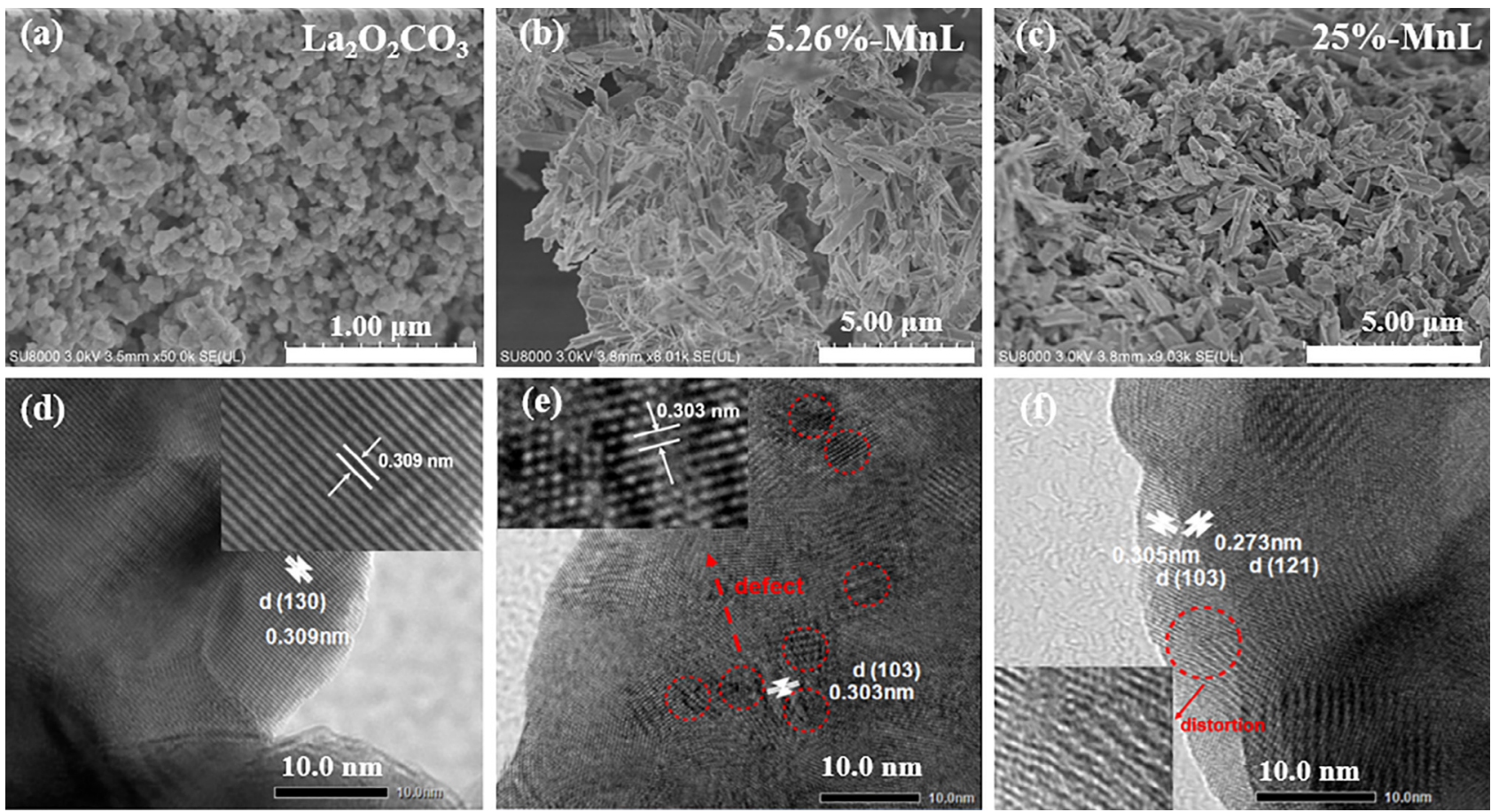

Fig. 2. FESEM images of $\mathrm{La}_{2} \mathrm{O}_{2} \mathrm{CO}_{3}$ (a); 5.26\%-MnL (b); $25 \%-\mathrm{MnL}$ (c) and HRTEM image of $\mathrm{La}_{2} \mathrm{O}_{2} \mathrm{CO}_{3}$ (d); 5.26\%-MnL (e); $25 \%-\mathrm{MnL}$ (f). 

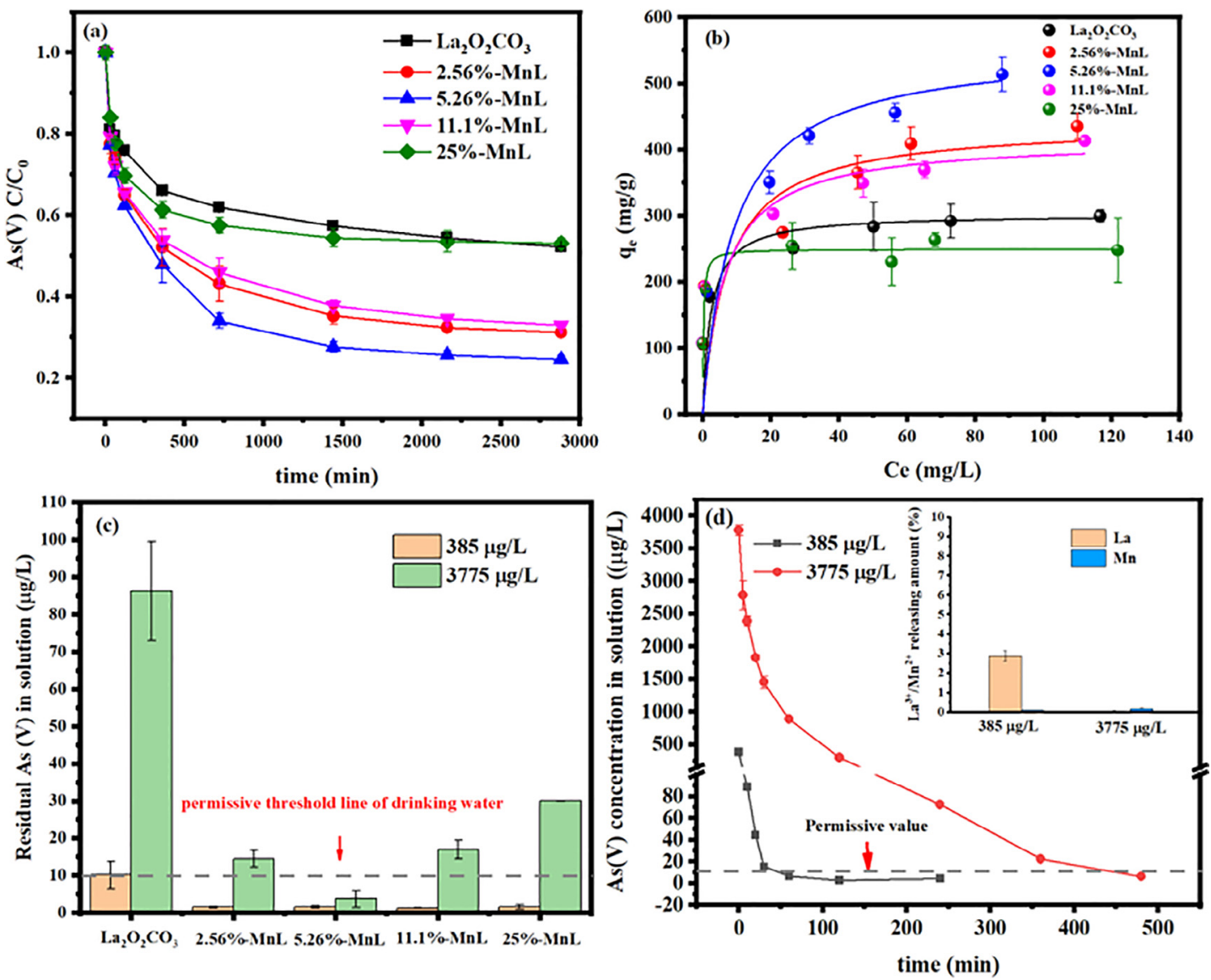

Fig. 3. (a). Adsorption kinetics of $\mathrm{La}_{2} \mathrm{O}_{2} \mathrm{CO}_{3}$ and $\mathrm{x}-\mathrm{MnL}$ towards $\mathrm{As}(\mathrm{V})$. Initial $\mathrm{As}(\mathrm{V})=50 \mathrm{mg} / \mathrm{L}$, adsorbents dosage $=0.1 \mathrm{~g} / \mathrm{L}, \mathrm{pH}=7.0, \mathrm{~T}=25^{\circ} \mathrm{C}$. (b). Adsorption isotherms of $\mathrm{La}_{2} \mathrm{O}_{2} \mathrm{CO}_{3}$ and $\mathrm{x}-\mathrm{MnL}$. Initial $\mathrm{As}(\mathrm{V})=10-200 \mathrm{mg} / \mathrm{L}$, adsorbents dosage $=0.1 \mathrm{~g} / \mathrm{L}, \mathrm{pH}=7.0, \mathrm{~T}=25^{\circ} \mathrm{C}$. (c). Residual arsenate in solution treated by $\mathrm{La}_{2} \mathrm{O}_{2} \mathrm{CO}_{3}$ and $\mathrm{x}-\mathrm{MnL}$ with initial concentration of $0.385 \mathrm{mg} / \mathrm{L}$ and $3.775 \mathrm{mg} / \mathrm{L}$.(d). Residual arsenate in solution treated by $5.26 \%-\mathrm{MnL}$ as a function of time. Adsorbents dosage $=0.1 \mathrm{~g} / \mathrm{L}, \mathrm{pH}_{0}=7.0, \mathrm{I}=0.01 \mathrm{~mol} / \mathrm{L} \mathrm{NaNO}{ }_{3} . \mathrm{T}=25^{\circ} \mathrm{C}$, reaction time $=12 \mathrm{~h}$.

$50 \% \mathrm{As}(\mathrm{V})$ was removed in the first $6 \mathrm{~h}$ and the final value reached $75.3 \%$ after $48 \mathrm{~h}$. To further determine the kinetic parameters, pseudofirst and pseudo-second order models were applied to fit the adsorption process. The model simulation of arsenate adsorption by both $\mathrm{x}-\mathrm{MnL}$ and $\mathrm{La}_{2} \mathrm{O}_{2} \mathrm{CO}_{3}$ (Table S1, Fig. S3a-b) were better fitted to the pseudosecond order model indicated by the higher correlation coefficients $\left(\mathrm{R}^{2}>0.995\right)$. This indicated that chemisorption, rather than physical interaction, predominated arsenate removal [14].

For a more complete understanding of the diffusion steps involved during adsorption, the intraparticle diffusion model (Weber-Morris Model) was applied to fit the kinetic data. As illustrated in Fig. S3c, two distinguishable linear plots with totally different slopes can be observed for all of the adsorbents. The results suggested that two diffusion processes presented during arsenate adsorption [10], where the first stage was due to the rapid bulk diffusion or external adsorption, and here 5.26\%-MnL exhibited the highest diffusion rate (Table S1). The second stage of the process, resulting in the more gentle slope in Fig.S3c, could be ascribed to intraparticle diffusion, which may be considered to be the rate liming step. As the fitting curve did not pass through the origin (Fig. S3c), not only intraparticle diffusion, but also chemical interaction and boundary layer control, could be considered to influence arsenate removal [35-37].

\subsubsection{Adsorption isotherms}

An adsorption isotherm study was conducted in order to evaluate the adsorption capabilities of the synthesized adsorbents (Fig. 3b). Langmuir and Freundlich models were applied separately to simulate the experimental data. As illustrated in Fig. S4, the Langmuir isotherm model exhibited better fitting results than the Freundlich model, suggesting of the monolayer adsorption behavior on $\mathrm{x}-\mathrm{MnL}[11,14]$. According to the Langmuir model, the maximum adsorption capacity was promoted as the content of Mn increased to $5.26 \%$, after which a decreasing trend with further increases in the doping amount of Mn (Table S2) was observed. The decreased adsorption capacities of $11.1 \%$ $\mathrm{MnL}$ and 25\%-MnL could be ascribed to the less adsorption sites or else by the decrease in surface activity owing to the presence of much more composite $\mathrm{LaMnO}_{3}$, which individually was proven to show quite poor adsorption capability towards arsenate (Fig. S5). By regulating doping dosage, 5.26\%-MnL exhibited superior adsorption performance with a maximum adsorption capacity of $555.6 \mathrm{mg} / \mathrm{g}$, much higher than most other adsorbents which have been reported (Table 1). Moreover, $5.26 \%-\mathrm{MnL}$ could reduce the arsenate concentrations to 1.6 and $3.7 \mu \mathrm{g} /$ $\mathrm{L}$ after $8 \mathrm{~h}$ at the initial concentration of 0.385 and $3.775 \mathrm{mg} / \mathrm{L}$, respectively (Fig. 3c-d). This performance allowed the treated solutions to meet the current drinking water regulations with arsenate concentration below $10 \mu \mathrm{g} / \mathrm{L}$. Furthermore, the amounts of $\mathrm{Mn}$ and La released from the adsorbent, during the adsorption process were $<3 \%$ and $<$ $0.2 \%$, respectively (Fig. $3 \mathrm{~d}$ ). It should be noted that the distribution coefficient $\left(\mathrm{K}_{\mathrm{d}}\right)$ value of $5.26 \%$-MnL was of the order of $10^{4} \sim 10^{7} \mathrm{~mL} / \mathrm{g}$ even at the initial $\mathrm{As}(\mathrm{V})$ concentrations up to $\sim 80 \mathrm{mg} / \mathrm{L}$ (Table S3), which again supported the view that $5.26 \%-\mathrm{MnL}$ may be considered as an excellent adsorbent, which possessed a high preference towards arsenate over a wide range of concentrations [33].

\subsubsection{The impact of initial $p H$}

Arsenate adsorption is strongly dependent on the solution $\mathrm{pH}$ 
Table 1

Comparisons of maximum adsorption capacity of various adsorbents toward arsenate species.

\begin{tabular}{llll}
\hline Adsorbents & $\mathrm{q}_{\max }(\mathrm{mg} / \mathrm{g})$ & $\mathrm{pH}$ & Reference \\
\hline CoAl-LDH@boehmite & 38.5 & 8 & {$[1]$} \\
Lanthanum (La)-impregnated activated alumina & 26.3 & 7 & {$[38]$} \\
Fe-La hydroxide & 368 & 7 & {$[39]$} \\
$\mathrm{Mg}-\mathrm{Fe}-\mathrm{La}$ Hydrotalcite & 81.4 & 6.8 & {$[2]$} \\
$\mathrm{MPSAC}-\mathrm{La}(0.36)$ & 227.6 & 6 & {$[3]$} \\
$\mathrm{SPC@La-oxalate}$ & 144.6 & $3-8$ & {$[22]$} \\
$\mathrm{Cu}$ doped $\mathrm{Fe}_{3} \mathrm{O}_{4}$ & 42.9 & 5 & {$[9]$} \\
$\mathrm{Zn}_{\mathrm{x}} \mathrm{Fe}_{3-\mathrm{x}} \mathrm{O}_{4}$ & 7.86 & 7 & {$[14]$} \\
$\mathrm{Ce} \mathrm{doped} \mathrm{TiO}_{2}$ & 43.86 & 6.5 & {$[13]$} \\
$\mathrm{NiO} / \mathrm{Ni} @ \mathrm{C} 400$ & 454.94 & 3 & {$[10]$} \\
$\mathrm{La} \mathrm{O}_{2} \mathrm{CO}_{3}$ & 303 & 7 & This study \\
$5.26 \%-\mathrm{MnL}$ & 555.6 & 7 & This study \\
\hline
\end{tabular}

because charge distribution of both the adsorbent surface and the arsenate species can substantially change under different $\mathrm{pH}$ conditions [10]. In order to identify the influence of $\mathrm{pH}$ on adsorption capabilities of $5.26 \%-\mathrm{MnL}$ and of $\mathrm{La}_{2} \mathrm{O}_{2} \mathrm{CO}_{3}$, separate adsorption experiments were conducted over the initial $\mathrm{pH}$ range 4.1-9.3. As shown in Fig. 4a, the adsorption capacities of both $5.26 \%-\mathrm{MnL}$ and $\mathrm{La}_{2} \mathrm{O}_{2} \mathrm{CO}_{3}$ decreased along with the increasing initial $\mathrm{pH}$. The final $\mathrm{pH}$ of each system was measured to be higher than the initial $\mathrm{pH}$ value, indicating the release of basic moieties during the adsorption process. It should be noted that although there was a decrease in adsorption efficiency under alkaline conditions, the arsenate adsorption capacity of 5.26\%-MnL still exceeded $300 \mathrm{mg} / \mathrm{g}$, indicating that this material exhibited a good adsorption performance over a wide $\mathrm{pH}$ range. The reduced adsorption capacity under basic conditions could probably be attributed to electrostatic repulsion. Zeta potential measurements indicated the value of $\mathrm{pH}_{\mathrm{pzc}}$ of $\mathrm{x}-\mathrm{MnL}$ and of $\mathrm{La}_{2} \mathrm{O}_{2} \mathrm{CO}_{3}$ was closed (ca. 6.8-7.2) (Fig. 4b). Additionally, with $\mathrm{pH}$ decreasing from 4 to 11, the surface charge of all the samples changed from positive to negative. Nevertheless, over this wide $\mathrm{pH}$ range, $5.26 \%$-MnL still possessed more positive charge than $\mathrm{La}_{2} \mathrm{O}_{2} \mathrm{CO}_{3}$ and other Mn-doped $\mathrm{La}_{2} \mathrm{O}_{2} \mathrm{CO}_{3}$ composites. Since arsenate mainly exists as $\mathrm{H}_{2} \mathrm{AsO}_{4}{ }^{-}$at $\mathrm{pH} \mathrm{3-6}$ and $\mathrm{HAsO}_{4}{ }^{2-}$ at $\mathrm{pH}$ 8-10 [3], in alkaline condition, both arsenate species and the surface of adsorbents were more negative, thus leading to strong electrostatic repulsion between the two. There was less negative charge on the surface of $5.26 \%$ $\mathrm{MnL}$ at $\mathrm{pH} \geq 7$, thus mass transfer resistance was relatively weaker for $5.26 \%$-MnL than for other composites, which facilitating arsenate capture during the adsorption process.

\subsubsection{The impact of competing anions and reusability}

Common oxyanions, such as $\mathrm{SO}_{4}{ }^{2-}, \mathrm{SiO}_{3}{ }^{2-}, \mathrm{HCO}_{3}{ }^{-}$and $\mathrm{HPO}_{4}{ }^{2-}$ in natural and wastewaters may have adverse influences on arsenate adsorption due to competitive effects. Therefore, an investigation to evaluate the selectivity of $5.26 \%-\mathrm{MnL}$ for arsenate adsorption in the presence of interfering anions, was carried out. The results indicated that $\mathrm{SO}_{4}{ }^{2-}$ and $\mathrm{SiO}_{3}{ }^{2-}$ did not negatively affect arsenate adsorption, even at a high concentration of $100 \mathrm{mg} / \mathrm{L}$ (Fig. 5a). There was only a slight decrease in arsenate adsorption efficiency, from $99.7 \%$ to $95.2 \%$ and $90.9 \%$, respectively when $\mathrm{HCO}_{3}{ }^{-}$and $\mathrm{HPO}_{4}{ }^{2-}$ were present in low concentration of $10 \mathrm{mg} / \mathrm{L}$. Significant lower adsorption efficiency occurred when the concentrations of $\mathrm{HCO}_{3}{ }^{-}$and $\mathrm{HPO}_{4}{ }^{2-}$ were further increased to $100 \mathrm{mg} / \mathrm{L}$, which may be ascribed to the higher amounts of competing anions present. Since the $\mathrm{K}_{\mathrm{sp}}$ value of $\mathrm{La}_{2}\left(\mathrm{CO}_{3}\right)_{3}$ $\left(\mathrm{K}_{\mathrm{sp}}=3.98 \times 10^{-34}\right)$ was lower than that of $\mathrm{LaAsO}_{4}$ $\left(\mathrm{K}_{\mathrm{sp}}=1.07 \times 10^{-21}\right)[21,40]$, the presence of $\mathrm{HCO}_{3}{ }^{-}$might compete for the adsorption sites with arsenate and lead to the lower $\mathrm{As}(\mathrm{V})$ adsorption capacity of $79.5 \%$. Additionally, phosphate possesses a similar molecular structure to that of arsenate and might block active sites by forming La/Mn-O-P bonds $[20,41]$, further reducing the adsorption efficiency of $\mathrm{As}(\mathrm{V})$ to $23.8 \%$. However, it is reported that the concentration of $\mathrm{HPO}_{4}{ }^{2-}$ in natural waters is generally less than $1 \mathrm{mg} / \mathrm{L}$ [42]. Therefore, the adverse effect of competing oxyanions on arsenate adsorption for $5.26 \%-\mathrm{MnL}$ was slight in water systems of low or medium basicity, confirming that $5.26 \%$-MnL possessed a satisfactory anti-interference ability.

The recyclability of $5.26 \%-\mathrm{MnL}$ was also evaluated. It is evident that after three adsorption-desorption cycles, the removal efficiency of As (V) was still comparatively good, at $85 \%$ (Fig. 5b). Correspondingly, the elution efficiencies during the desorption test had slightly decreased from $90 \%$ to $79 \%$ by the third adsorption cycle (Fig. S6). The decreased adsorption and elution efficiencies may be caused by the gradual loss of available active sites after each cycle. The elution efficiency of the 5.26\%-MnL reached $90 \%$ during the initial As(V) adsorption experiment, after which the morphology of the adsorbent was again characterized (Fig. S7) as evidence from which to evaluate the stability of the material. The reused 5.26\%-MnL adsorbent, after $\mathrm{NaOH}$ elution, retained a generally-similar rod-like morphology to the fresh $5.26 \%$ $\mathrm{MnL}$ adsorbent, indicating good structural stability of the adsorbent for reutilization. Thus, in terms of removal capability of $\mathrm{As}(\mathrm{V})$ over a wide pH range, good anti-interference ability and satisfactory reusability, the synthesized 5.26\%-MnL can be suggested as a promising adsorbent for sustainable arsenate remediation.

\subsection{Arsenate adsorption mechanisms}

It was interesting to find that following treatment by $5.26 \%-\mathrm{MnL}$, the final $\mathrm{pH}$ value of the processed solution was firstly increased and

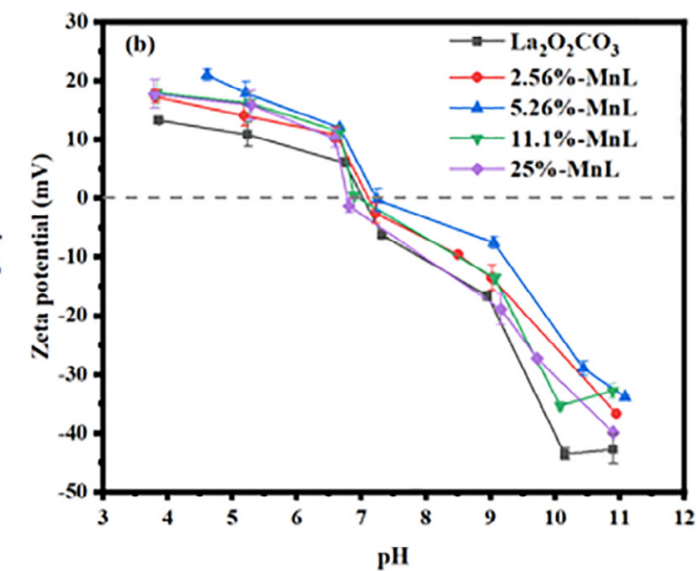

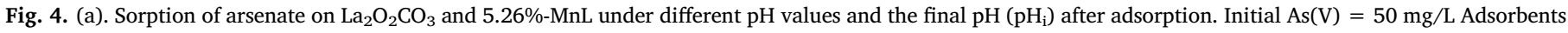
dosage $=0.1 \mathrm{~g} / \mathrm{L}, \mathrm{T}=25{ }^{\circ} \mathrm{C}$. (b). Zeta potential of $\mathrm{La}_{2} \mathrm{O}_{2} \mathrm{CO}_{3}$ and $\mathrm{x}-\mathrm{MnL}$ at different solution $\mathrm{pH}(\mathrm{x}=2.56 \%, 5.26 \%, 11.1 \%, 25 \%)$. 

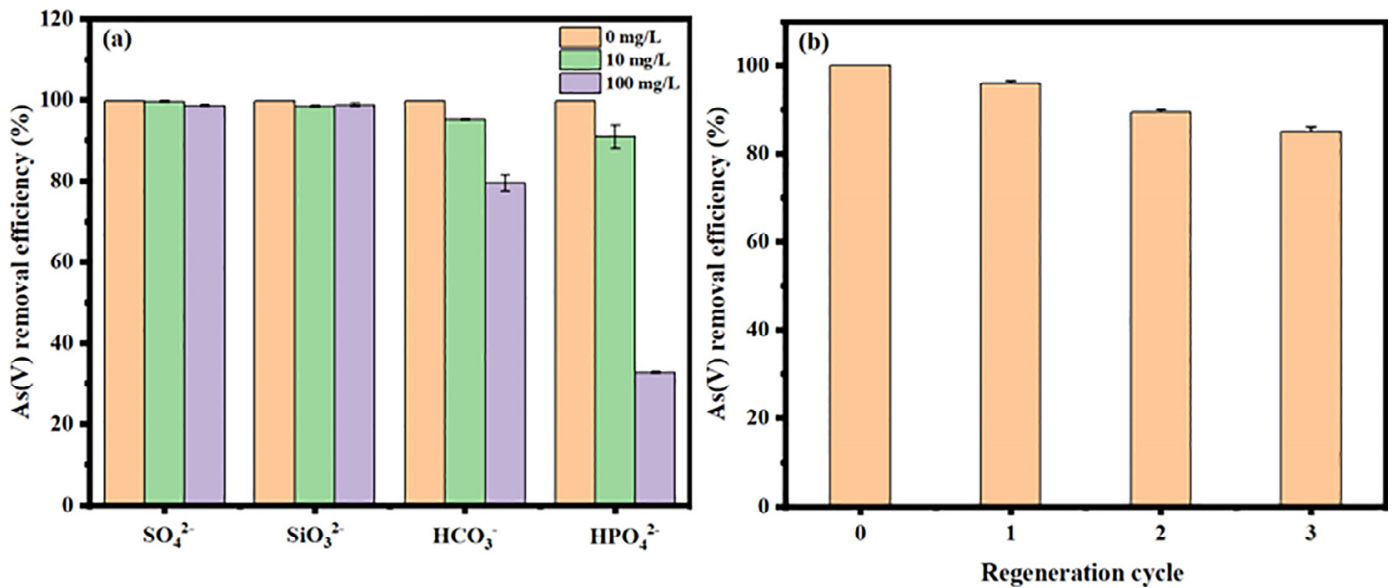

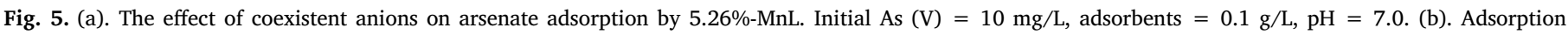
efficiency of As (V) on 5.26\%-MnL under different regeneration cycles. Initial As $(\mathrm{V})=10 \mathrm{mg} / \mathrm{L}$, adsorbents $=0.2 \mathrm{~g} / \mathrm{L}, \mathrm{pH}=7.0$, $\mathrm{T}=25{ }^{\circ} \mathrm{C}$.

then decreased along with increasing initial arsenate concentrations from $100 \mathrm{mg} / \mathrm{L}$ to $500 \mathrm{mg} / \mathrm{L}$ (Fig. S8). It was hypothesised that the adsorption mechanisms were differing under diverse arsenate concentrations, which can be reflected in the molar ratio of As(V)/ 5.26\%MnL. Therefore, the mechanism was separately investigated at low and high $\mathrm{As}(\mathrm{V}) / 5.26 \%-\mathrm{MnL}$ ratios.
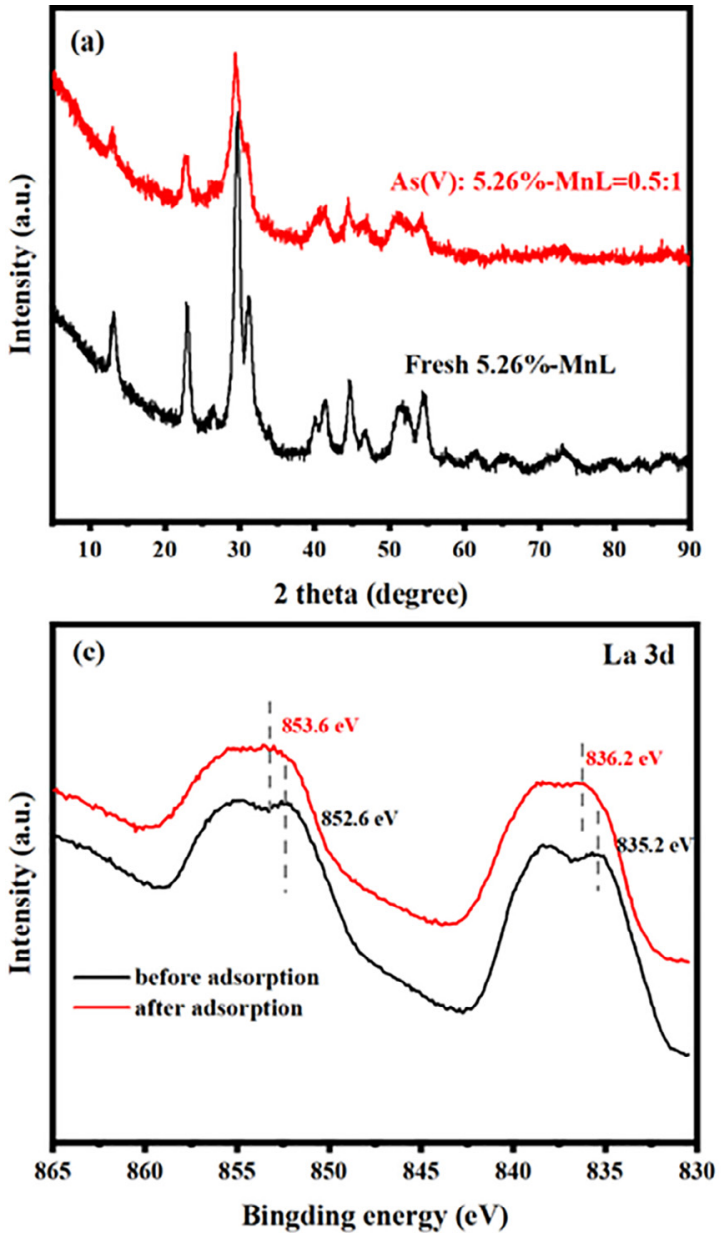

\subsubsection{Arsenate removal at low $\mathrm{As}(\mathrm{V}) / \mathrm{MnL}$ ratio}

After the adsorption experiment performed with an arsenate concentration of $100 \mathrm{mg} / \mathrm{L}(\mathrm{As}(\mathrm{V}) / 5.26 \%-\mathrm{MnL}$ ratio of $0.5: 1)$, the adsorbent was collected for characterization and compared with the original adsorbent. The XRD pattern of 5.26\%-MnL after adsorption was almost identical to the fresh sample, except for the lower intensity, suggesting that no new crystalline phase had obviously formed during adsorption (Fig. 6a). However, the chemical properties of the adsorbent
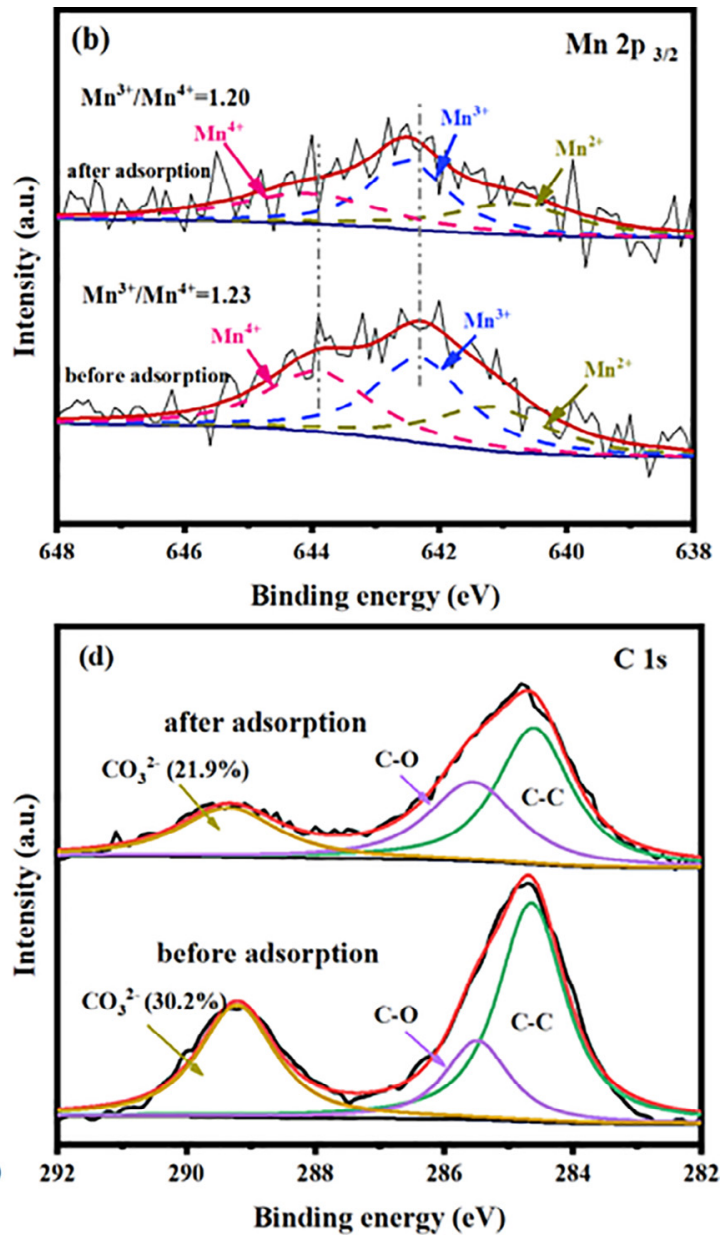

Fig. 6. (a) XRD patterns of fresh and used adsorbents in $\mathrm{As}(\mathrm{V}) / 5.26 \%-\mathrm{MnL}=0.5: 1$ system. (b)-(d) XPS spectra of 5.26\%-MnL before and after adsorption in As(V)/ $5.26 \%-\mathrm{MnL}=0.5: 1$ system. ((b): $\mathrm{Mn} 2 \mathrm{p}_{3 / 2} ;$ (c): La 3d; (d):C1s). Adsorbent dosage was fixed as $1 \mathrm{~g} / \mathrm{L}, \mathrm{As}(\mathrm{V})=100 \mathrm{mg} / \mathrm{L}, \mathrm{pH}=7.0$. 
had markedly changed (Fig. 6b-d and Fig. S9). The peaks for $\mathrm{Mn}^{3+}$ $(642.3 \mathrm{eV})$ and $\mathrm{Mn}^{4+}(643.9 \mathrm{eV})$ in XPS spectra after adsorption exhibited a blue shift (ca. $0.2 \mathrm{eV}$ ) to higher binding energies (Fig. 6b), implying that both $\mathrm{Mn}^{3+}$ and $\mathrm{Mn}^{4+}$ had complexed with $\mathrm{HAsO}_{4}{ }^{2-}$ through ligand exchange $[11,14,43]$. The negligible change in molar ratio of $\mathrm{Mn}^{3+} / \mathrm{Mn}^{4+}$ suggested that a redox reaction was not involved during adsorption. Similar to Mn $2 \mathrm{p}_{3 / 2}$, a blue shift (ca. $1 \mathrm{eV}$ ) and sharply decreased intensity for La 3d after adsorption were also noted, indicating the formation of La-O-As complexes (Fig. 6c) [2,44]. Meanwhile, the neglected effect of ionic strength on arsenate removal further confirmed the formation of an inner sphere complex $\mathrm{M}-\mathrm{O}-\mathrm{As}$ $\left(\mathrm{M}=\mathrm{La}, \mathrm{Mn}\right.$ ) [44] (Fig. S10). By forming an inner complex, $\mathrm{OH}^{-}$ would be released, which was supported by the $O 1 \mathrm{~s}$ spectra where surface oxygen species (ie. $\mathrm{O}_{2}{ }^{-} /-\mathrm{OH}$ ) located at $531.1 \mathrm{eV}$ [45] decreased from $61.5 \%$ to $38.1 \%$ after adsorption (Fig.S9c). Thus the $\mathrm{pH}$ value increased as a result (Eq. (4)). With reference to the $\mathrm{C} 1 \mathrm{~s}$ signal (Fig. 6d), the content of $\mathrm{CO}_{3}{ }^{2-}(289.2 \mathrm{eV})$ decreased from $30.2 \%$ to $21.9 \%$ after adsorption, indicating that $\mathrm{CO}_{3}{ }^{2-}$ in the interlayer of $\left(\mathrm{La}_{2} \mathrm{O}_{2}\right)^{2+}$ were removed by $\mathrm{HAsO}_{4}{ }^{2-}$ through anionic exchange. Therefore, at low ratios of $\mathrm{As}(\mathrm{V}) / 5.26 \%-\mathrm{MnL}$, both anion exchange and surface complexing contributed to arsenate removal and released both $\mathrm{OH}^{-}$and $\mathrm{CO}_{3}{ }^{2-}$, which would induce elevated $\mathrm{pH}$.

$\equiv \mathrm{M}-\mathrm{OH}+\mathrm{HAsO}_{4}^{2-} \rightarrow \equiv \mathrm{M}-\mathrm{O}-\mathrm{As}+2 \mathrm{OH}^{-}$

\subsubsection{Arsenate removal at high $A s(V) / M n L$ ratio}

As illustrated by the XRD patterns in Fig. 7a, the intensities of characteristic peaks of $\mathrm{LaAsO}_{4}$ (JCPDS card 15-0756) gradually increased as the molar ratio of $\mathrm{As}(\mathrm{V}) / 5.26 \%-\mathrm{MnL}$ increased from $1: 1$ to 2:1 (As(V) concentration increased from $200 \mathrm{mg} / \mathrm{L}$ to $500 \mathrm{mg} / \mathrm{L}$ ), which suggested that precipitation between $\mathrm{La}^{3+}$ and $\mathrm{HAsO}_{4}{ }^{2-}$ had occurred under a higher concentration of arsenate. Accompanying $\mathrm{LaAsO}_{4}$ production, $\mathrm{H}^{+}$was released, thus causing a decrease in $\mathrm{pH}$ (Eq. (5)). Moreover, the amount of total carbonate $\left(\mathrm{HCO}_{3}{ }^{-}+\mathrm{CO}_{3}{ }^{2-}\right)$ liberated also increased with increasing initial $\mathrm{As}(\mathrm{V})$ concentration, indicating the occurrence of anion exchange even under higher arsenate concentrations (Fig. 7b). The release of total $\mathrm{OH}^{-}\left(1.328 \mathrm{mmol} / \mathrm{L} \mathrm{OH}^{-}\right)$ was much higher than the concentration of $\mathrm{OH}^{-}$derived from $\mathrm{CO}_{3}{ }^{2-}$ hydrolyzation $\left(0.582 \mathrm{mmol} / \mathrm{L} \mathrm{OH}^{-}, K_{h l, C O}^{2-}=2.08 \times 10^{-4}\right)$ [46] at As (V)/5.26\%-MnL ratio of 1:1, implying that under that condition, excess $\mathrm{OH}^{-}$probably came from complexation processes, through the exchange of ligand $\mathrm{O}^{2-}$ in the $\left(\mathrm{La}_{2} \mathrm{O}_{2}\right)^{2+}$ layer with arsenate. Although the precipitation of $\mathrm{LaAsO}_{4}$ occurred, the contribution of it was relatively small so that the final $\mathrm{pH}$ continued to increase. When As (V):5.26\%-MnL $=2: 1$, the available complex sites could be saturated and excess of $\mathrm{HAsO}_{4}{ }^{2-}$ would combine with $\mathrm{La}^{3+}$ rapidly to form $\mathrm{LaAsO}_{4}$, resulting in decreased amounts of $\mathrm{La}^{3+}$ at the end of reaction (Fig. S11). During precipitation, an abundance of $\mathrm{H}^{+}$would be produced, thus giving rise to high $\mathrm{HCO}_{3}{ }^{-}$production (Eq. (6)) and a decreased $\mathrm{OH}^{-}$(Fig. 7b). Therefore, at high ratios of $\mathrm{As}(\mathrm{V}) / 5.26 \%-\mathrm{MnL}$, surface precipitation played an important role in removal of arsenate besides inner complexation and anion exchange.

$\mathrm{La}^{3+}+\mathrm{HAsO}_{4}^{2-} \rightarrow \mathrm{LaAsO}_{4}+\mathrm{H}^{+}$

$\mathrm{CO}_{3}^{2-}+\mathrm{H}^{+} \rightarrow \mathrm{HCO}_{3}^{-}$

In summary, the process of arsenate adsorption by Mn-doped $\mathrm{La}_{2} \mathrm{O}_{2} \mathrm{CO}_{3}$ can be described as follows. At low As(V)/MnL ratio, arsenate complexation sites were sufficient, thus surface complexation and ion exchange would take place preferentially. However, at high ratio of $\mathrm{As}(\mathrm{V}) / \mathrm{MnL}$, the complexing sites became gradually occupied and excess of $\mathrm{HAsO}_{4}{ }^{2-}$ combined with $\mathrm{La}^{3+}$ directly to form $\mathrm{LaAsO}_{4}$ as precipitates, accompanied by of the liberation of $\mathrm{HCO}_{3}{ }^{-}$. These findings indicated that, even in practical, complex water systems with various arsenate concentrations, the doping of $\mathrm{La}_{2} \mathrm{O}_{2} \mathrm{CO}_{3}$ with $\mathrm{Mn}$ will produce a material with excellent characteristics for arsenate remediation via a range of changeable reaction pathways.

\subsection{DFT calculation}

Density function of theory (DFT) calculation was performed in order to understand the functions of $\mathrm{Mn}$ atoms on arsenate removal at a molecular level. The $\left(\begin{array}{lll}1 & 0 & 3\end{array}\right)$ plane was chosen as the adsorption plane due to the distinguished intensity in XRD patterns. The optimized configurations of this plane in Mn-doped $\mathrm{La}_{2} \mathrm{O}_{2} \mathrm{CO}_{3}$, before and after arsenate adsorption, are depicted in Fig. 8. In accordance with previous discussions, La and Mn were set as adsorption sites. Therefore, before adsorption, an arsenate molecule was placed above a Mn atom (Fig. 8b) and La atoms near doping sites (Fig. 8c) separately. Meanwhile, the interaction of $\mathrm{La}$ atoms with arsenate in pure $\mathrm{La}_{2} \mathrm{O}_{2} \mathrm{CO}_{3}$ (Fig. 8a) was also studied as a comparison. The adsorption energy ( $\mathrm{E}_{\mathrm{ads}}$ ) of the process that arsenate interacted with pure $\mathrm{La}_{2} \mathrm{O}_{2} \mathrm{CO}_{3}$ was calculated to be $-2.51 \mathrm{eV}$ (Fig. 8d), indicative of chemical interaction between arsenate and the adsorbent. For MnL, there was a strong Mn-O-As bond formed and the adsorption energy of this configuration was calculated to be $-4.17 \mathrm{eV}$ (Fig. 8e). This value was markedly lower than that of $\mathrm{As}(\mathrm{V})$ on La site in pure $\mathrm{La}_{2} \mathrm{O}_{2} \mathrm{CO}_{3}$, implying that arsenate adsorption on $\mathrm{Mn}$ sites was more favourable than that on La sites. Moreover, after doping with $\mathrm{Mn}$ atoms, $\mathrm{E}_{\mathrm{ads}}$ of arsenate on the La sites located near the doping site also decreased to $-3.50 \mathrm{eV}$ (Fig. 8f), which suggested that the
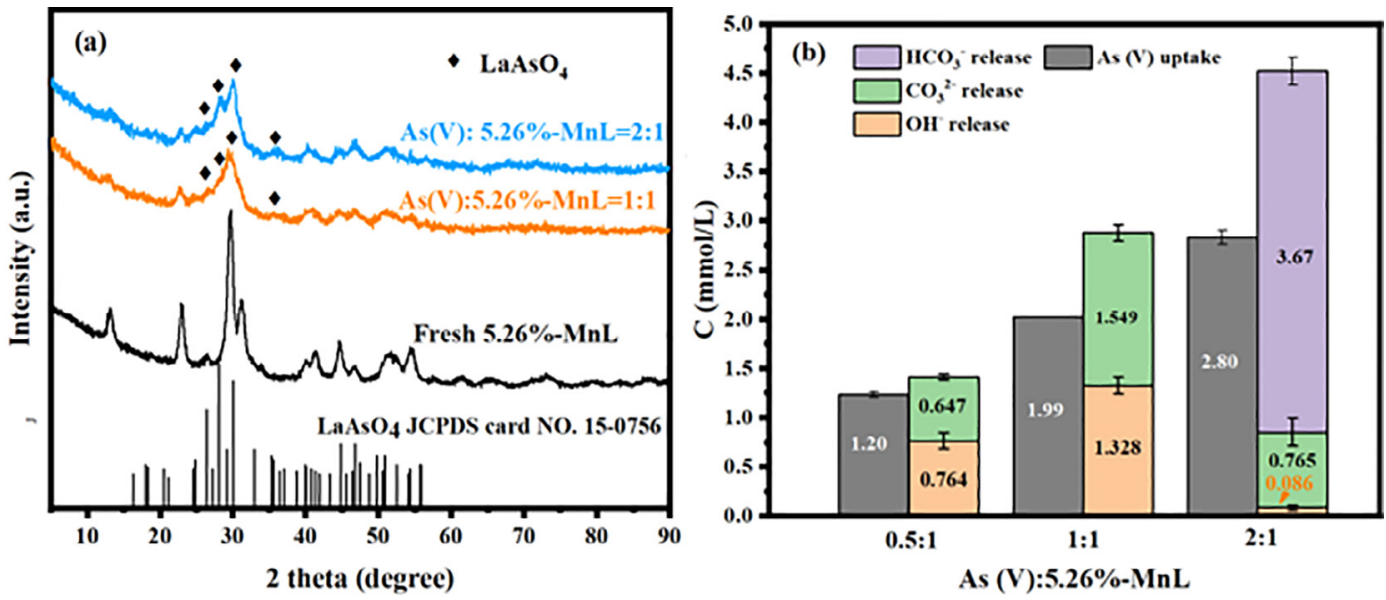

Fig. 7. (a). XRD patterns of 5.26\%-MnL before and after adsorption in As (V)/5.26\%-MnL $=1: 1$ and 2:1 systems(As (V) $=200 \mathrm{mg} / \mathrm{L}$ and $500 \mathrm{mg} / \mathrm{L}$, respectively). (b). The uptake amount of $\mathrm{As}(\mathrm{V})$ and releasing amount of $\mathrm{OH}^{-}, \mathrm{CO}_{3}{ }^{2-}$ and $\mathrm{HCO}_{3}{ }^{-}$in different $\mathrm{As}(\mathrm{V}) / \mathrm{MnL}$ systems. Adsorbents dosage was fixed as $1 \mathrm{~g} / \mathrm{L}$, $\mathrm{pH}_{0}=7.0$. 


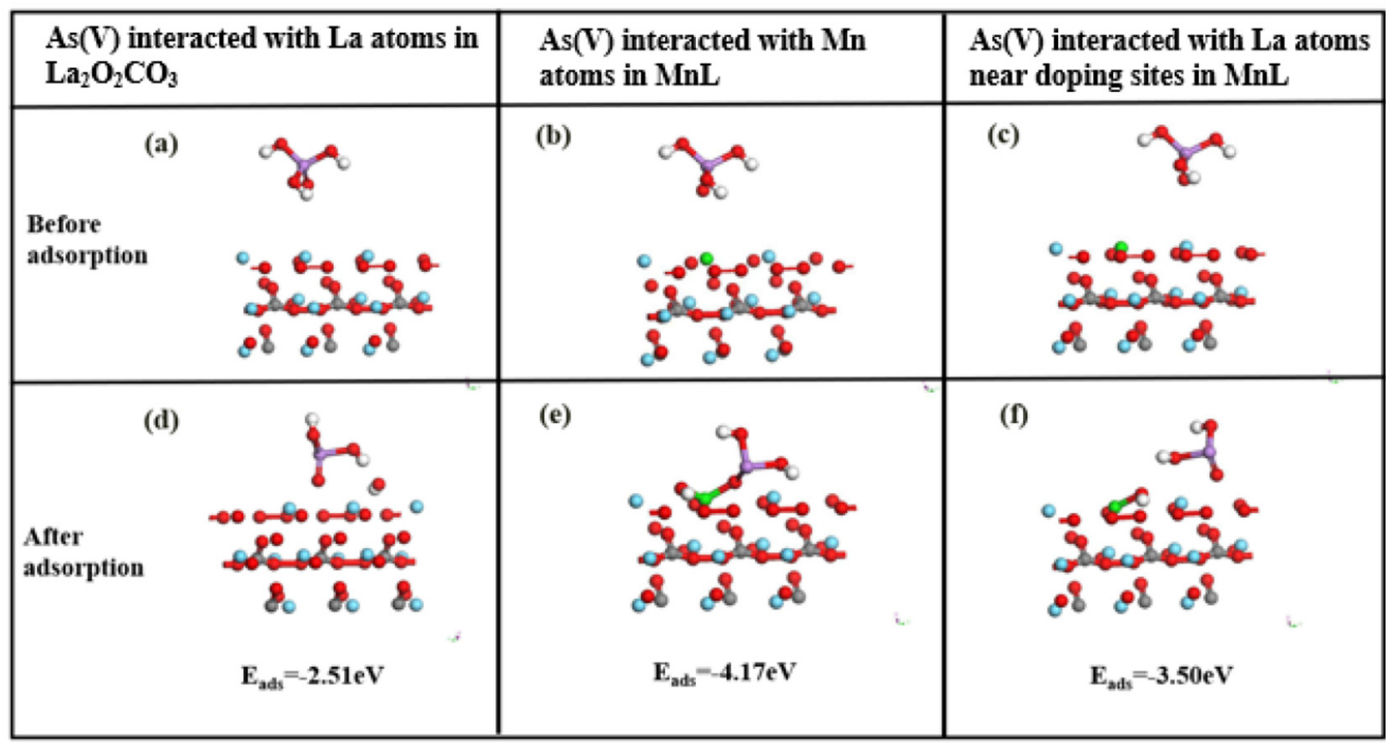

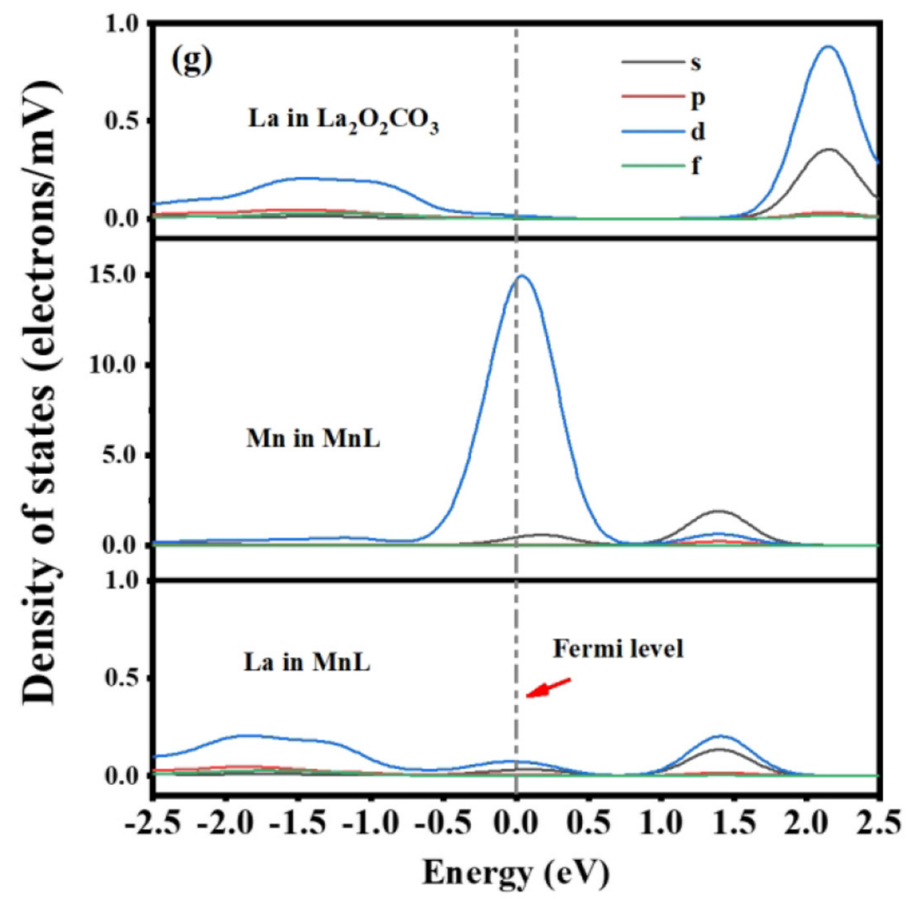

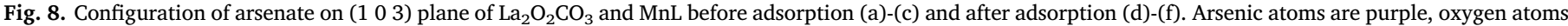

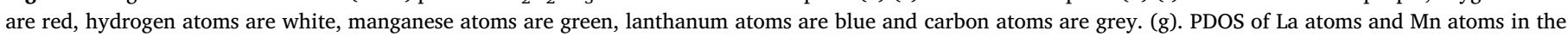
doped and un-doped adsorbents. (For interpretation of the references to colour in this figure legend, the reader is referred to the web version of this article.)

interaction between $\mathrm{As}(\mathrm{V})$ and La atoms was facilitated after Mn doping and that the adsorption product of $\mathrm{Mn}$ doped $\mathrm{La}_{2} \mathrm{O}_{2} \mathrm{CO}_{3}$ was more stable. Therefore, the results suggested that $\mathrm{Mn}$ atoms acted as active species not only providing extra adsorption sites but also lowering the adsorption energy of the interaction process, which made arsenate more favourably adsorbed.

Partial Density of States (PDOS) of La atoms and Mn atoms in Mndoped $\mathrm{La}_{2} \mathrm{O}_{2} \mathrm{CO}_{3}$ were also investigated to figure out how the surface properties changed after Mn doping. In Fig. $8 \mathrm{~g}$, it may be observed that the PDOS, at the Fermi level, of Mn atoms in a Mn-doped lattice was much more intense than that of $\mathrm{La}$ atoms in pure $\mathrm{La}_{2} \mathrm{O}_{2} \mathrm{CO}_{3}$. Since electrons are more active at around the Fermi level than at other valence bands, the intensity of PDOS close to the Fermi level is an indicative of how reactive those atoms are [47]. Therefore, Mn atoms in $\mathrm{MnL}$ were more active towards arsenate. For the same reason, the activity of La atoms after Mn doping also increased when compared to La atoms in pure $\mathrm{La}_{2} \mathrm{O}_{2} \mathrm{CO}_{3}$, which may probably be ascribed to facile electron transfer through Mn doping. Hence, it is demonstrated that doping with $\mathrm{Mn}$ atoms increased the activity of formerly pristine adsorption sites (La atoms), resulting in more favourable interfacial reactions and better adsorption performance.

\section{Conclusions}

In this study, Mn-doped $\mathrm{La}_{2} \mathrm{O}_{2} \mathrm{CO}_{3}(\mathrm{MnL})$ was fabricated via one step sol-gel process as a novel effective adsorbent for arsenate decontamination. By regulating doping amount of $\mathrm{Mn}$ atoms, it was found that $5.26 \%-M n L$ exhibited abundant lattice defects and showed superior adsorption capacity $(555.6 \mathrm{mg} / \mathrm{g}$ ) towards arsenate, which was much higher than that of most reported adsorbents. The residual 
arsenate after treatment was well below the permissible threshold for drinking water, with little release of $\mathrm{La}^{3+}$ and $\mathrm{Mn}^{2+}$, which supports the potential safety of the adsorption application. The reusability of $5.26 \%-\mathrm{MnL}$ and its resilience towards competing anions (ie. $\mathrm{SO}_{4}{ }^{2-}$, $\mathrm{SiO}_{3}{ }^{2-}, \mathrm{HCO}_{3}{ }^{-}$and $\mathrm{HPO}_{4}{ }^{2-}$ ) in aqueous systems of low or medium basicity were verified to be satisfactory. A relatively high adsorption capacity was also achieved over a wide $\mathrm{pH}$ range. Study into the adsorption mechanism revealed that inner surface complexation and anion exchange dominated arsenate removal at low $\mathrm{As}(\mathrm{V}) / \mathrm{MnL}$ ratios, while formation of precipitated $\mathrm{LaAsO}_{4}$ gradually played more important role when $\mathrm{As}(\mathrm{V})$ concentration was higher. DFT calculations showed that doping with Mn atoms would increase active sites, activate La atoms and reduce the energy of adsorption, thus improving adsorption performance. Those experimental and theoretical results proved that doping by $\mathrm{Mn}$ atoms provided an effective strategy by which to boost arsenate adsorption, to increase active sites and strengthen the chemical interaction of $\mathrm{La}_{2} \mathrm{O}_{2} \mathrm{CO}_{3}$, opening up the possible utilization of $\mathrm{Mn}$-doped $\mathrm{La}_{2} \mathrm{O}_{2} \mathrm{CO}_{3}$ for arsenate remediation.

\section{Declaration of Competing Interest}

The authors declare that they have no known competing financial interests or personal relationships that could have appeared to influence the work reported in this paper.

\section{Acknowledgements}

This work was supported by the National Key R\&D Program of China (2017YFA0207204), the National Natural Science Foundation of China (Grant No. 21806175) and Medical Technologies and Advanced Materials Strategic Theme at Nottingham Trent University. We thank Dr Mick Cooper for proof reading.

\section{Appendix A. Supplementary data}

Supplementary data to this article can be found online at https:// doi.org/10.1016/j.cej.2019.123623.

\section{References}

[1] S.Y. Lee, K.-W. Jung, J.-W. Choi, Y.J. Lee, In situ synthesis of hierarchical cobaltaluminum layered double hydroxide on boehmite surface for efficient removal of arsenate from aqueous solutions: Effects of solution chemistry factors and sorption mechanism, Chem. Eng. J. 368 (2019) 914-923.

[2] P. Wu, L. Xia, Y. Liu, J. Wu, Q. Chen, S. Song, Simultaneous Sorption of Arsenate and Fluoride on Calcined Mg-Fe-La Hydrotalcite-Like Compound from Water, ACS Sustainable Chem. Eng. 6 (2018) 16287-16297.

[3] F.M. Jais, S. Ibrahim, Y. Yoon, M. Jang, Enhanced arsenate removal by lanthanum and nano-magnetite composite incorporated palm shell waste-based activated carbon, Sep. Purif. Technol. 169 (2016) 93-102.

[4] N. Kumari, A. Rana, S. Jagadevan, Arsenite biotransformation by Rhodococcus sp. Characterization, optimization using response surface methodology and mechanistic studies, Sci. Total Environ. 687 (2019) 577-589.

[5] W. Quaghebeur, R.E. Mulhern, S. Ronsse, S. Heylen, H. Blommaert, S. Potemans, C. Valdivia Mendizabal, J. Terrazas Garcia, Arsenic contamination in rainwater harvesting tanks around Lake Poopo in Oruro, Bolivia: An unrecognized health risk, Sci. Total Environ. 688 (2019) 224-230.

[6] J. Hong, L. Liu, Y. Luo, W. Tan, G. Qiu, F. Liu, Photochemical oxidation and dissolution of arsenopyrite in acidic solutions, Geochim. Cosmochim. Acta 239 (2018) 173-185.

[7] G. Zhang, X. Xu, Q. Ji, R. Liu, H. Liu, J. Qu, J. Li, Porous Nanobimetallic Fe-Mn Cubes with High Valent Mn and Highly Efficient Removal of Arsenic(III), ACS Appl. Mater. Interfaces 9 (2017) 14868-14877.

[8] L. Liu, W. Tan, S.L. Suib, G. Qiu, L. Zheng, S. Su, Enhanced adsorption removal of arsenic from mining wastewater using birnessite under electrochemical redox reactions, Chem. Eng. J. 375 (2019).

[9] T. Wang, W. Yang, T. Song, C. Li, L. Zhang, H. Wang, L. Chai, Cu doped $\mathrm{Fe}_{3} \mathrm{O}_{4}$ magnetic adsorbent for arsenic: synthesis, property, and sorption application, RSC Adv. 5 (2015) 50011-50018.

[10] Z. Lv, Q. Fan, Y. Xie, Z. Chen, A. Alsaedi, T. Hayat, X. Wang, C. Chen, MOFs-derived magnetic chestnut shell-like hollow sphere NiO/Ni@C composites and their removal performance for arsenic(V), Chem. Eng. J. 362 (2019) 413-421.

[11] Y. Gu, D. Xie, Y. Wang, W. Qin, H. Zhang, G. Wang, Y. Zhang, H. Zhao, Facile fabrication of composition-tunable Fe/Mg bimetal-organic frameworks for exceptional arsenate removal, Chem. Eng. J. 357 (2019) 579-588.

[12] C. Wu, Y. Xu, S. Xu, J. Tu, C. Tian, Z. Lin, Enhanced adsorption of arsenate by spinel zinc ferrite nano particles: Effect of zinc content and site occupation, J. Environ. Sci. 79 (2019) 248-255.

[13] Z. Li, J. Qu, H. Li, T.C. Lim, C. Liu, Effect of cerium valence on As(V) adsorption by cerium-doped titanium dioxide adsorbents, Chem. Eng. J. 175 (2011) 207-212.

[14] J. Luo, X. Meng, J. Crittenden, J. Qu, C. Hu, H. Liu, P. Peng, Arsenic adsorption on $\alpha-\mathrm{MnO}_{2}$ nanofibers and the significance of (100) facet as compared with (110), Chem. Eng. J. 331 (2018) 492-500.

[15] S. Li, Y. Guo, M. Xiao, T. Zhang, S. Yao, S. Zang, H. Fan, Y. Shen, Z. Zhang, W. Li, Enhanced arsenate removal from aqueous solution by Mn-doped MgAl-layered double hydroxides, Environ. Sci. Pollut. Res. Int. 26 (2019) 12014-12024.

[16] H.-J. Cui, J.-K. Cai, J.-W. Shi, B. Yuan, C.-L. Ai, M.-L. Fu, Fabrication of 3D porous $\mathrm{Mn}$ doped $\alpha-\mathrm{Fe}_{2} \mathrm{O}_{3}$ nanostructures for the removal of heavy metals from wastewater, RSC Adv. 4 (2014) 10176-10179.

[17] L. Yu, X.J. Peng, J. Li, F. Ni, Z.K. Luan, Removal of As (V) and As (III) from water using Mn-doped maghemite nanoparticles, Fresenius Environ. Bull. 23 (2014) 508-515.

[18] Z. Qi, T.P. Joshi, R. Liu, H. Liu, J. Qu, Synthesis of Ce(III)-doped $\mathrm{Fe}_{3} \mathrm{O}_{4}$ magnetic particles for efficient removal of antimony from aqueous solution, J. Hazard. Mater. 329 (2017) 193-204.

[19] Q. Mu, Y. Wang, Synthesis, characterization, shape-preserved transformation, and optical properties of $\mathrm{La}(\mathrm{OH}) 3$, La2O2CO3, and La2O3 nanorods, J. Alloy. Compd. 509 (2011) 396-401.

[20] Y. Wei, P. Yuan, D. Liu, D. Losic, D. Tan, F. Chen, H. Liu, J. Zhou, P. Du, Y. Song, Activation of natural halloysite nanotubes by introducing lanthanum oxycarbonate nanoparticles via co-calcination for outstanding phosphate removal, Chem. Commun. (Camb.) 55 (2019) 2110-2113.

[21] X. Zhang, F. Sun, J. He, H. Xu, F. Cui, W. Wang, Robust phosphate capture over inorganic adsorbents derived from lanthanum metal organic frameworks, Chem. Eng. J. 326 (2017) 1086-1094.

[22] S. Muthu Prabhu, C. Chuaicham, K. Sasaki, A Mechanistic Approach for the Synthesis of Carboxylate-Rich Carbonaceous Biomass-Doped Lanthanum-Oxalate Nanocomplex for Arsenate Adsorption, ACS Sustainable Chem. Eng. 6 (2018) 6052-6063.

[23] F. Zhang, X. Zhang, G. Jiang, N. Li, Z. Hao, S. Qu, $\mathrm{H}_{2}$ S selective catalytic oxidation over Ce substituted $\mathrm{La}_{1-} \mathrm{Ce}_{\mathrm{x}} \mathrm{FeO}_{3}$ perovskite oxides catalyst, Chem. Eng. J. 348 (2018) 831-839.

[24] X. Tian, P. Gao, Y. Nie, C. Yang, Z. Zhou, Y. Li, Y. Wang, A novel singlet oxygen involved peroxymonosulfate activation mechanism for degradation of ofloxacin and phenol in water, Chem. Commun. (Camb.) 53 (2017) 6589-6592.

[25] Z. Li, X. Liu, W. Jin, Q. Hu, Y. Zhao, Adsorption behavior of arsenicals on MIL101(Fe): The role of arsenic chemical structures, J. Colloid Interface Sci. 554 (2019) 692-704.

[26] W. Wang, Q. Zhu, F. Qin, Q. Dai, X. Wang, Fe doped $\mathrm{CeO}_{2}$ nanosheets as Fenton-like heterogeneous catalysts for degradation of salicylic acid, Chem. Eng. J. 333 (2018) 226-239.

[27] X. Yang, Q. Gao, Z. Zhao, Y. Guo, Y. Guo, L. Wang, Y. Wang, W. Zhan, Surface tuning of noble metal doped perovskite oxide by synergistic effect of thermal treatment and acid etching: A new path to high-performance catalysts for methane combustion, Appl. Catal. B 239 (2018) 373-382.

[28] K. Xuan, X. Zhu, Y. Cai, X. Tu, Plasma Oxidation of $\mathrm{H}_{2} \mathrm{~S}$ over Non-stoichiometric $\mathrm{La}_{\mathrm{x}} \mathrm{MnO}_{3}$ Perovskite Catalysts in a Dielectric Barrier Discharge Reactor, Catalysts 8 (2018) 1-13.

[29] K. Chen, X. Duan, H. Fang, X. Liang, Y. Yuan, Selective hydrogenation of $\mathrm{CO}_{2}$ to methanol catalyzed by $\mathrm{Cu}$ supported on rod-like $\mathrm{La}_{2} \mathrm{O}_{2} \mathrm{CO}_{3}$, Catal. Sci. Technol. 8 (2018) 1062-1069.

[30] R.E. Przekop, P. Marciniak, B. Sztorch, A. Czapik, M. Stodolny, A. Martyła, One-pot synthesis of $\mathrm{Al}_{2} \mathrm{O}_{3}-\mathrm{La}_{2} \mathrm{O}_{2} \mathrm{CO}_{3}$ systems obtained from the metallic precursor by the sol-gel method, J. Non-Cryst. Solids 479 (2018) 105-112.

[31] N. Erdenee, U. Enkhnaran, S. Galsan, A. Pagvajav, Lanthanum-Based PerovskiteType Oxides $\mathrm{La}_{1-\mathrm{x}} \mathrm{Ce}_{\mathrm{x}} \mathrm{BO}_{3}(\mathrm{~B}=\mathrm{Mn}$ and $\mathrm{Co})$ as Catalysts: Synthesis and Characterization, J. Nanomater. 2017 (2017) 1-8.

[32] J.-W. Kou, S.-Y. Cheng, J.-L. Bai, Effects of amino trimethylene phosphonic acid on structure and properties of $\mathrm{Cu}-\mathrm{Zn}-\mathrm{Al}$ hydrotalcite-derived oxides for catalytic synthesis of iso-butanol and ethanol from synthesis gas, Fuel 255 (2019) 1-10.

[33] W. Pu, Z. Song, J. Yan, H. Xu, H. Ji, S. Yuan, H. Li, Preparation of oxygen-deficient $2 \mathrm{D} \mathrm{WO}_{3-\mathrm{x}}$ nanoplates and their adsorption behaviors for organic pollutants: equilibrium and kinetics modeling, J. Mater. Sci. 54 (2019) 12463-12475.

[34] R. Xu, M. Zhang, R.J. Mortimer, G. Pan, Enhanced Phosphorus Locking by Novel Lanthanum/Aluminum-Hydroxide Composite: Implications for Eutrophication Control, Environ. Sci. Technol. 51 (2017) 3418-3425.

[35] Z. Zhang, P. Gu, M. Zhang, S. Yan, L. Dong, G. Zhang, Synthesis of a robust layered metal sulfide for rapid and effective removal of $\mathrm{Sr}^{2+}$ from aqueous solutions, Chem. Eng. J. 372 (2019) 1205-1215.

[36] Q. Wang, L. Yang, F. Jia, Y. Li, S. Song, Removal of Cd (II) from water by using nano-scale molybdenum disulphide sheets as adsorbents, J. Mol. Liq. 263 (2018) $526-533$.

[37] J. Su, L. Bi, C. Wang, T. Lyu, G. Pan, Enhancement of cadmium removal by oxygendoped carbon nitride with molybdenum and sulphur hybridization, J. Colloid Interface Sci. 556 (2019) 606-615.

[38] Q. Shi, L. Yan, T. Chan, C. Jing, Arsenic Adsorption on Lanthanum-Impregnated Activated Alumina: Spectroscopic and DFT Study, ACS Appl. Mater. Interfaces 7 (2015) 26735-26741.

[39] W. Zhang, J. Fu, G. Zhang, X. Zhang, Enhanced arsenate removal by novel Fe-La 
composite (hydr)oxides synthesized via coprecipitation, Chem. Eng. J. 251 (2014) 69-79.

[40] S. Tokunaga, S. Yokoyama, S. Wasay, Removal of Arsenic(III) and Arsenic(V) Ions from Aqueous Solutions with Lanthanum(III) Salt and Comparison with Aluminum (III), Calcium(II), and Iron(III) Salts, Water Environ. Res. 71 (1999) 299-306.

[41] T. Zhang, N.N. Tham, Z. Liu, A. Fisher, J.Y. Lee, Promotion of the bifunctiona electrocatalytic oxygen activity of manganese oxides with dual-affinity phosphate, Electrochim. Acta 277 (2018) 143-150.

[42] F. Xie, F. Wu, G. Liu, Y. Mu, C. Feng, H. Wang, J.P. Giesy, Removal of phosphate from eutrophic lakes through adsorption by in situ formation of magnesium hydroxide from diatomite, Environ. Sci. Technol. 48 (2014) 582-590.

[43] H. Wang, Y.-N. Wang, Y. Sun, X. Pan, D. Zhang, Y.F. Tsang, Differences in Sb(V) and $\mathrm{As}(\mathrm{V})$ adsorption onto a poorly crystalline phyllomanganate ( $\delta$-MnO2): Adsorption kinetics, isotherms, and mechanisms, Process Saf. Environ. Prot. 113 (2018) 40-47. [44] X. Liu, E. Zong, W. Hu, P. Song, J. Wang, Q. Liu, Z. Ma, S. Fu, Lignin-Derived Porous Carbon Loaded with $\mathrm{La}(\mathrm{OH})_{3}$ Nanorods for Highly Efficient Removal of Phosphate, ACS Sustainable Chem. Eng. 7 (2018) 758-768.

[45] Q. Wu, J. Xiong, Y. Zhang, X. Mei, Y. Wei, Z. Zhao, J. Liu, J. Li, Interaction-Induced Self-Assembly of $\mathrm{Au} @ \mathrm{La}_{2} \mathrm{O}_{3}$ Core-Shell Nanoparticles on $\mathrm{La}_{2} \mathrm{O}_{2} \mathrm{CO}_{3}$ Nanorods with Enhanced Catalytic Activity and Stability for Soot Oxidation, ACS Catal. 9 (2019) 3700-3715.

[46] T.F. Dunlap, R.A. Kohn, Calculation of the Buffering Capacity of Bicarbonate in the Rumen and In Vitro, J. Anim. Sci. 76 (1998) 1702-1709.

[47] H. Yi, X. Zhang, F. Jia, Z. Wei, Y. Zhao, S. Song, Competition of $\mathrm{Hg}^{2+}$ adsorption and surface oxidation on $\mathrm{MoS}_{2}$ surface as affected by sulfur vacancy defects, Appl. Surf. Sci. 483 (2019) 521-528. 